\title{
Relationship between low-density lipoprotein cholesterol, lipid-lowering agents and risk of stroke: a meta-analysis of observational studies $(n=355,591)$ and randomized controlled trials $(n=165,988)$
}

Maciej Banach ${ }^{1,2,3}$, Niloofar Shekoohi ${ }^{4}$, Dimitri P. Mikhailidis ${ }^{5}$, Gregory Y.H. Lip ${ }^{6}$, Adrian V. Hernandez ${ }^{7,8}$, Mohsen Mazidi ${ }^{9,10,11}$, on behalf of the Lipid and Blood Pressure Meta-analysis Collaboration (LBPMC) Group and the International Lipid Expert Panel (ILEP)

${ }^{1}$ Department of Preventive Cardiology and Lipidology, Medical University of Lodz (MUL), Lodz, Poland

2Polish Mother's Memorial Hospital Research Institute (PMMHRI), Lodz, Poland ${ }^{3}$ Cardiovascular Research Centre, University of Zielona Gora, Zielona Gora, Poland ${ }^{4}$ Department of Cellular and Molecular Nutrition, School of Nutritional Sciences and Dietetics, Tehran University of Medical Sciences, Tehran, Iran

${ }^{5}$ Department of Clinical Biochemistry, Royal Free Campus, University College London Medical School, University College London (UCL), London, UK

${ }^{6}$ Liverpool Centre for Cardiovascular Science, University of Liverpool and Liverpool Heart and Chest Hospital, Liverpool, UK

${ }^{7}$ Health Outcomes, Policy, and Evidence Synthesis (HOPES) Group, University of Connecticut/Hartford Hospital Evidence-Based Practice Center, Hartford, CT, USA ${ }^{8}$ Vicerrectorado de Investigacion, Universidad San Ignacio de Loyola (USIL), Lima, Peru ${ }^{9}$ Department of Twin Research and Genetic Epidemiology, King's College London, London, UK

${ }^{10}$ Medical Research Council Population Health Research Unit, University of Oxford, Oxford, UK

${ }^{11}$ Clinical Trial Service Unit and Epidemiological Studies Unit (CTSU), Nuffield

Department of Population Health, University of Oxford, Oxford, UK

Submitted: 5 January 2022; Accepted: 19 January 2022

Online publication: 19 January 2022

Arch Med Sci 2022; 18 (4): 912-929

DOI: https://doi.org/10.5114/aoms/145970

Copyright $\odot 2022$ Termedia \& Banach

\begin{abstract}
Introduction: The impact of low-density lipoprotein cholesterol (LDL-C) on the risk of different types of strokes is unclear. Therefore, we systematically evaluated the impact of LDL-C levels (cohort studies) and lipid-lowering agents (LLAs) (randomized controlled trials) on the different types of stroke. Material and methods: PubMed, SCOPUS, Web of Science and Google Scholar were searched up to $1^{\text {st }}$ September 2019. The DerSimonian-Laird method and generic inverse variance methods were used for quantitative data synthesis. The leave-one-out method was performed as sensitivity analysis. Trial sequential analysis (TSA) was used to evaluate the optimal sample size to detect a $35 \%$ reduction in outcomes after administration of LLAs.

Results: Participants in the highest category of LDL-C had a lower risk of hemorrhagic stroke $\left(\mathrm{RR}=0.91,95 \% \mathrm{Cl}: 0.85-0.98, I^{2}=0 \%\right)$ compared with the lowest category of LDL-C. Subjects with the highest category of LDL-C had a higher risk of ischemic stroke (RR $\left.=1.11,95 \% \mathrm{Cl}: 1.07-1.14, I^{2}=0 \%\right)$ compared to the lowest LDL-C category. LLAs decreased the risk of all types of strokes for those who achieved LDL-C $<1.8 \mathrm{mmol} / \mathrm{l}(<70 \mathrm{mg} / \mathrm{dl} ; \mathrm{RR}=0.88$, 95\% Cl: 0.80-0.96, absolute risk reduction (ARR): $0.7 \%$, number needed to treat (NNT): $143, l^{2}=53 \%, n=13$ ). Statin therapy decreased the risk of all strokes (RR $=0.88,95 \% \mathrm{Cl}: 0.80-0.97, \mathrm{ARR}=0.6 \%, \mathrm{NNT}=167, l^{2}=56 \%$ ). With regard to ischemic stroke only, LLAs decreased the risk of ischemic
\end{abstract}

\author{
Corresponding authors: \\ Prof. Maciej Banach \\ MD, PhD, FNLA, FAHA \\ FESC, FASA \\ Department of \\ Preventive Cardiology \\ and Lipidology \\ Medical University of Lodz \\ 281/289 Rzgowska St \\ 93-338 Lodz, Poland \\ Phone: +48422711124 \\ E-mail: maciejbanach77@ \\ gmail.com \\ Dr. Mohsen Mazidi PhD \\ Department of Twin \\ Research and Genetic \\ Epidemiology \\ King's College London \\ London, UK \\ E-mail: mohsen.mazidi@ \\ ndph.ox.ac.uk
}


stroke for those who achieved LDL-C $<1.8 \mathrm{mmol} / \mathrm{l}(<70 \mathrm{mg} / \mathrm{dl}$; RR $=0.75,95 \% \mathrm{Cl}: 0.67-0.83, \mathrm{ARR}=1.3 \%$, $\left.\mathrm{NNT}=77, I^{2}=0 \%\right)$; the same was observed for statins $(\mathrm{RR}=0.76,95 \% \mathrm{Cl}: 0.69-0.84, \mathrm{ARR}=1.3 \%, \mathrm{NNT}=77$, $\left.I^{2}=32 \%\right)$. TSA indicated that both benefit boundaries and optimal sample size were reached. There was no significant effect of LLAs regardless of the achieved level of LDL-C on the risk of hemorrhagic stroke; however, TSA indicated that further studies are needed to settle the question and most of the effects were subject to high levels of heterogeneity.

Conclusions: Our study sheds light on the debatable association between low LDL-C and different type of strokes. This information can help determine the optimal LDL-C range for stroke prevention, and help plan future LLA studies.

Key words: low-density lipoprotein cholesterol, systematic review, meta-analysis, stroke.

\section{Introduction}

Dyslipidemia is a leading risk factor for coronary heart disease (CHD) [1, 2], but its effects on the pathogenesis of stroke are less clear [3-10]. There are some inconsistencies regarding the relationship between cholesterol and ischemic stroke [3-9]. A meta-analysis of 900,000 individuals from 61 prospective cohort studies did not find any significant relationship between total cholesterol and fatal stroke risk [10]. However, risk of the first stroke was reduced in statin trials that included populations at high risk of vascular events; this effect was associated with lowering low-density lipoprotein cholesterol (LDL-C) levels [11-13]. In a meta-analysis of 65,138 individuals with 2282 strokes (204 hemorrhagic, 1565 ischemic, 513 unknown type), a significant proportional reduction in the incidence of the first stroke of any type was observed among participants treated with lipid-lowering agents (LLAs) [14]. There are several factors that may account for these conflicting results. First, stroke is a heterogeneous condition with various etiologies; so lipid abnormalities may be related to some subtypes of stroke but not others [15]. Secondly, lipoprotein sub-fractions have different impacts on stroke risk [16]. The association between LDL-C and different types of strokes, therefore, needs to be more carefully evaluated.

The impact of lipid-lowering medications on stroke types has not been well established and is still a matter of considerable debate [17]. Although there is some evidence with regard to the effectiveness of lipid-lowering agents on the risk of stroke (mainly ischemic) [18-21], some trials in which individuals were treated with non-statin therapy showed no (significant) reduction in the risk of stroke [22]. Moreover, a meta-analysis of statin trials reported a non-significant association between statin therapy and the risk of hemorrhagic stroke [23]. In another systematic review and meta-analysis of non-statin clinical trials aiming for further LDL-C lowering, a non-significant positive association between LDL-C lowering and increased risk of hemorrhagic stroke was reported
[24]. Recent randomized controlled trials (RCTs) demonstrated that statins significantly decrease vascular events in primary and secondary prevention of myocardial infarction [25-31]. A reduction in the risk of strokes (ischemic, transient ischemic attack (TIA) and brain hemorrhage) was reported in only 3 of these trials $[25,26,29]$. Recent trials with PCSK9 inhibitors suggested a significant association between combination therapy and reduced risk of ischemic stroke, and a lack of significant difference in hemorrhagic stroke between groups [32, 33].

Due to the paucity of studies and conflicting findings, we performed the present analysis to obtain more insights into LDL-C in relation to different types of stroke events based on observational studies. We also performed a systematic search and meta-analysis on the impact of LLAs and risk of different types of stroke based on RCTs; finally, we applied trial sequential analysis (TSA) to determine whether the pooled trial data provided sufficient evidence to reach a reliable conclusion regarding the effect of LLAs and risk of different types of stroke.

\section{Material and methods}

\section{Cohort studies}

\section{Literature search}

The meta-analysis was reported according to the Meta-analysis Of Observational Studies in Epidemiology (MOOSE) guidelines [34]. The primary exposure of interest was LDL-C level while the primary outcomes were different types of stroke. Prospective cohort studies published up to $1 \mathrm{Sep}$ tember 2019 without language restriction were searched using PubMed, Embase, and Scopus databases; the query syntax of PubMed is shown in Supplementary Table SI. This was complemented by additional searches of the reference list of eligible articles, and email correspondence with authors for additional data where relevant.

After excluding duplicates and based on titles and abstracts, we excluded studies in animals, and in those $<18$ years old. Eligible studies were 
M. Banach, N. Shekoohi, D.P. Mikhailidis, G.Y.H. Lip, A.V. Hernandez, M. Mazidi, on behalf of the Lipid and Blood Pressure Meta-analysis Collaboration (LBPMC) Group and the International Lipid Expert Panel (ILEP)

selected by using predefined inclusion criteria of prospective cohort studies, and original articles on the association of LDL-C and stroke risk. In addition, a supplementary search of reference lists of previous reviews or meta-analyses was conducted.

\section{Study selection}

Titles and abstracts were screened by two reviewers (MM and NS). To avoid selection bias, the reviewers were blinded to the names, qualifications and institutional affiliations of the study authors. The agreement between the reviewers was excellent ( $\kappa$ index: 0.90; $p<0.001$ ). Disagreements were resolved at a meeting between the authors prior to selected articles being retrieved.

We included studies if they met all the following criteria: (1) exposure was LDL-C; (2) population-based cohort studies and reported stroke risk data; (3) relative risk (RR), hazard ratio (HR) or odds ratio (OR) estimates with $95 \%$ confidence interval (Cl) adjusted for multivariable factors were available or could be calculated. Narrative reviews, comments, opinion pieces, methodological reports, editorials, letters or any other publications lacking primary data and/or explicit method descriptions were excluded.

\section{Risk of bias assessment and data extraction}

Full texts meeting the inclusion criteria were retrieved and screened to determine eligibility by two reviewers (MM and NS). The study risk of bias assessment was performed according to the Newcastle-Ottawa Scale (NOS, Supplementary Table SII) [35]. By evaluation of selection, comparability and outcome, the NOS scores studies from 0 (highest degree of bias) to 9 (lowest degree of bias). Additionally we investigated the funding sources of all of the eligible studies. Following assessment of methodological quality, two reviewers (MM and NS) extracted data using a purpose-designed data extraction form and independently summarized the most important results from each study. These summaries were compared and any differences of opinion resolved by discussion and consultation with a third reviewer (MB). Any further calculations on study data considered necessary were conducted by the first reviewer and checked by the second reviewer. Information extracted from each eligible study included the following items: author, year and references, study name, \% of men, mean age, follow-up time (years), number of individuals overall, categories of LDL-C levels, number of individuals per LDL-C category, main confounders, number of strokes per LDL-C category, type of strokes.

\section{Statistical analysis}

For studies that reported results from different multivariable-adjusted models, the model with the most confounding factors was extracted for analyses. The random-effect model with inverse variance method was applied to calculate pooled RRs, 95\% Cl and $p$-value for heterogeneity. RRs comparing the highest category of LDL with the lowest category of LDL were combined across studies to generate the summary associations. The extent of heterogeneity across studies was examined using the $I^{2}$ test [3638] and an $l^{2}>50 \%$ together with two-sided $p<0.05$ indicated significant heterogeneity [36-38].

\section{Publication bias}

Potential publication bias was explored using visual inspection of Begg's funnel plot asymmetry, Begg's rank correlation and Egger's weighted regression tests. The Duval and Tweedie trim method was used to adjust the analysis for the effects of publication bias [39]. Meta-analysis was conducted using Comprehensive Meta-Analysis (CMA) V3 software (Biostat, NJ) [40].

\section{Randomized controlled trials}

\section{Literature search}

We reported this study according to the Preferred Reporting Items for Systematic Reviews and Meta-Analyses (PRISMA) Guidelines [41, 42]. We searched multiple databases, including PubMed/ Medline, Cochrane Central Register of Controlled Trials (CCTR), Cochrane Database of Systematic Reviews (CDSR), and Web of Science by Clarivate and www.clinicaltrials.gov register until $1^{\text {st }}$ September 2019 using a combination of search terms (Supplementary Table SIII). This was complemented by a hand search of the reference list of eligible articles, and email correspondence with authors for additional data where relevant.

\section{Study selection}

We included RCTs evaluating the effect of pravastatin, lovastatin, atorvastatin, simvastatin, fluvastatin, cerivastatin, rosuvastatin, pitavastatin, HMG-CoA reductase inhibitor, statin, ezetimibe, proprotein convertase subtilisin/kexin type 9 (PCSK9) inhibitors, alirocumab, evolocumab or bococizumab on the outcomes of interest. Eligible studies had to meet the following criteria: (1) an RCT with either parallel or crossover design, (2) studies of patients treated with mentioned agents compared with a control group (either with no lipid-lowering agents or placebo), and, (3) containing sufficient information on the primary outcome at end of follow-up in each group. The primary outcome was stroke. 
Exclusion criteria were: (i) non-clinical studies, (ii) observational studies with case-control, cross-sectional or cohort design, (iii) sample size $<2000$ participants, and (iv) duration of treatment $<2$ years. Narrative reviews, comments, opinion pieces, methodological, editorials, letters or any other publications lacking primary data and/or explicit method descriptions were also excluded. Study selection started with the removal of duplicates; then titles and abstracts were screened by two reviewers (MM and NS). To avoid selection bias, they were blinded to the names, qualifications and institutional affiliations of the study authors. The agreement between the reviewers was excellent ( $\kappa$ index: 0.92; $p<0.001$ ). Disagreements were resolved at a meeting between reviewers prior to selected articles being retrieved.

\section{Data extraction}

Full texts were retrieved and screened to determine eligibility by two reviewers (MM, NS). Following assessment of methodological quality, the same two reviewers extracted data into a purpose-designed data extraction form, and independently summarized what they considered to be the most important results from each study. These summaries were compared and any differences of opinion were resolved by discussion and consultation with the third reviewer (MB). Any further calculations on study data considered necessary were conducted by the first reviewer (MM) and checked by the second reviewer (NS). Descriptive data extracted included author(s) and references, study name, year of publication, country of origin, men (\%), mean age, mean follow-up (years), number of participants, type of intervention, type of control, number of participants per drug arm, baseline LDL cholesterol level, achieved LDL cholesterol level, strokes per drug arm, types of strokes, main confounders.

\section{Risk of bias assessment}

A systematic assessment of bias in the included RCTs was performed using the Cochrane tool [43]. The evaluated items were: adequacy of random sequence generation, allocation concealment, blinding of participants, personnel and outcome assessment, handling of drop-outs (incomplete outcome data), selective outcome reporting, and other potential sources of bias. Each item was judged as low risk, high risk or unclear risk (Supplementary Table SIV).

\section{Statistical analysis}

A DerSimonian-Laird random effects model and the generic inverse variance method were used to evaluate the effect of LLAs on stroke [43].
Heterogeneity was quantitatively assessed using the $I^{2}$ index. In order to evaluate the influence of each study on the overall effect size, sensitivity analysis was conducted using the leave-one-out method, i.e. removing one study each time and repeating the analysis [43]. The main effect measure was the RR and its $95 \% \mathrm{Cl}$. We also calculated the number needed to treat (NNT). NNT is the number of individuals required to experience the intervention in order to avoid one stroke.

We performed the following meta-analyses: (1) by levels of achieved LDL-C (achieved LDL-C level $\leq 1.3 \mathrm{mmol} / \mathrm{l}(50 \mathrm{mg} / \mathrm{dl}), 1.3 \mathrm{mmol} / \mathrm{l}(50 \mathrm{mg} / \mathrm{dl})$ to $<1.8 \mathrm{mmol} / \mathrm{l}(70 \mathrm{mg} / \mathrm{dl})$, and $\geq 1.8 \mathrm{mmol} / \mathrm{l}$ $70 \mathrm{mg} / \mathrm{dl}$ ); (2) by statin or non-statin group (statin trials vs. non-statin trials), (3) by primary vs secondary prevention, (4) separately by specific type of stroke: ischemic and hemorrhagic.

To reduce the risk of type I error caused by pooling data from the same trials or from trials with missing data, trial sequential analysis (TSA) was applied. Interim analysis of a single randomized trial avoids type I error by creating monitoring boundaries for an estimated difference between groups, so if the estimated difference is reached the trial could be terminated. TSA uses a similar accurate method to create monitoring boundaries and estimate the optimal sample size in meta-analyses. TSA performs a cumulative meta-analysis with the results of the available studies (represented by the Z-curve): as each new study is included, significance is tested and $\mathrm{Cls}$ are estimated. It also creates adjusted boundaries for benefit, harm, and futility, and estimates the optimal sample size for a given difference between treatment arms, so that a smaller estimated difference would result in wider boundaries and a greater optimal sample size. If one of the boundaries (benefit, risk or futility) or if the optimal sample size is reached, firm conclusions might be made (for that predefined difference) and further studies are deemed unnecessary; instead, if no boundaries are reached, further studies are needed to settle the question. Random errors were accounted for by calculating a diversity-adjusted required information size, which represented monitoring boundaries to determine whether the evidence in our cumulative meta-analysis was sufficient to reach a conclusion. It is also adjusted for the variability between trials and for the amount of available evidence. The required sample size for the TSA was estimated using two-side testing, $\alpha=0.05$ (two-sided), $\beta=0.20$ (power of $80 \%$ ), the incidence rate in the control group, and $35 \%$ relative risk reduction (RRR) in the LDL-lowering agents intervention group. Sensitivity analysis was conducted with $20 \%$ relative risk reduction in the LDL-lowering agents intervention group. TSA was conducted using TSA version 0.9 beta (Copen- 
M. Banach, N. Shekoohi, D.P. Mikhailidis, G.Y.H. Lip, A.V. Hernandez, M. Mazidi, on behalf of the Lipid and Blood Pressure Meta-analysis Collaboration (LBPMC) Group and the International Lipid Expert Panel (ILEP)

hagen Trial Unit, Copenhagen, Denmark; available at www.ctu.dk/tsa).

\section{Ethics}

This investigation uses published or publicly available summary data. No original data were collected for this manuscript. Ethical approval for each of the studies included in the present analysis can be found in the original publications (including informed consent from each participant). The study conforms to the ethical guidelines of the 1975 Declaration of Helsinki.

\section{Results}

\section{Cohort studies}

\section{Characteristics of the included studies}

Of 36 eligible full articles, 11 cohort studies were finally included in the meta-analysis (Figure 1). In total 355,591 participants with 11,888 events including stroke (3 studies), ischemic stroke (6 studies), hemorrhagic stroke (6 studies), intracerebral hemorrhage (2 studies), intraparenchymal hemorrhage ( 2 studies), cerebral infarction (1 study) and cerebral hemorrhage (1 study) were entered in the analysis. All studies included both sexes and two of them presented sex-specific results. The mean follow-up duration was 9.9 years (range: 4.9-19 years) (Table I).

We analyzed different types of stroke separately: any stroke [44-46], hemorrhagic stroke [44-49],

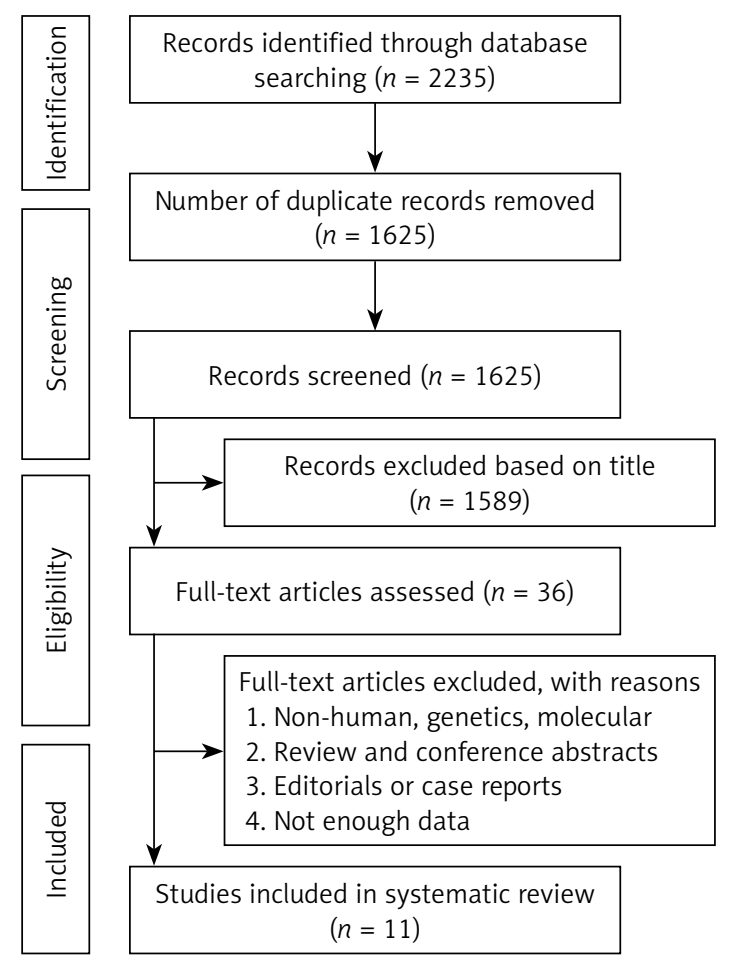

Figure 1. Flow chart for the selection of cohort studies ischemic stroke [44-49], intracerebral hemorrhage [50, 51], deep or infratentorial microbleeds [50], cerebral infarction [52] and cerebral hemorrhage [52].

\section{Risk of bias assessment}

Results of risk of bias assessment are shown in Supplementary Table SII, with 8 studies scoring $\geq 8$, and three studies with a score of 7 .

\section{Association between LDL-C levels and stroke}

The highest LDL-C quartile was not associated with stroke events in comparison to the lowest LDL-C quartile $(\mathrm{HR}=1.03,95 \% \mathrm{Cl}$ : 0.95-1.11, $p=0.4, n=3$ studies, Figure 2), with low heterogeneity of effects $\left(R^{2}=0 \%, p=1.0\right)$. Subjects in the highest LDL-C quartile had a lower risk of the hemorrhagic strokes $(\mathrm{HR}=0.91,95 \% \mathrm{Cl}: 0.85-0.98$, $p=0.012, n=7$ studies, Figure 3$)$, with low heterogeneity across studies $\left(R^{2}=0 \%, p=0.9\right)$. Subjects in the highest LDL-C quartile had a higher risk of ischemic stroke ( $\mathrm{HR}=1.11,95 \% \mathrm{Cl}: 1.07-1.14, p<$ $0.001, n=7$ studies, Figure 4), with low heterogeneity among studies $\left(R^{2}=0 \%, p=0.7\right)$. No significant association was found between LDL-C and intracerebral hemorrhage events $(\mathrm{HR}=0.99,95 \%$ $\mathrm{Cl}: 0.77-1.28, p=1.0, n=2$ studies; $I^{2}=0 \%, p=0.7$ ).

\section{Sensitivity analysis}

In leave-one-out sensitivity analyses, the pooled effect estimates were similar for the association between LDL-C and hemorrhagic stroke (HR = 0.91, 95\% Cl: 0.85-0.98) and for the association between LDL-C and ischemic stroke (HR = 1.10, 95\% Cl: 1.07-1.14). This stability confirms that the significant difference between the studied groups is the overall effect of all included studies.

\section{Publication bias}

Regarding the association between LDL-C and hemorrhagic stroke, Egger's linear regression indicated absence of publication bias (intercept = $-0.55,95 \% \mathrm{Cl}:-6.91,6.00, p=0.837)$; also, Begg's rank correlation test (Kendall's $\tau$ with continuity correction $=1.00, z=0.244$, two tailed $p=0.806$ ) did not indicate publication bias.

\section{RCTs}

\section{Study selection}

A flowchart of study selection is shown in Figure 5; a total of 6925 unique citations were identified from searches, of which 2599 records remained after removing duplicates. After screening via titles and abstracts, 103 articles remained for 


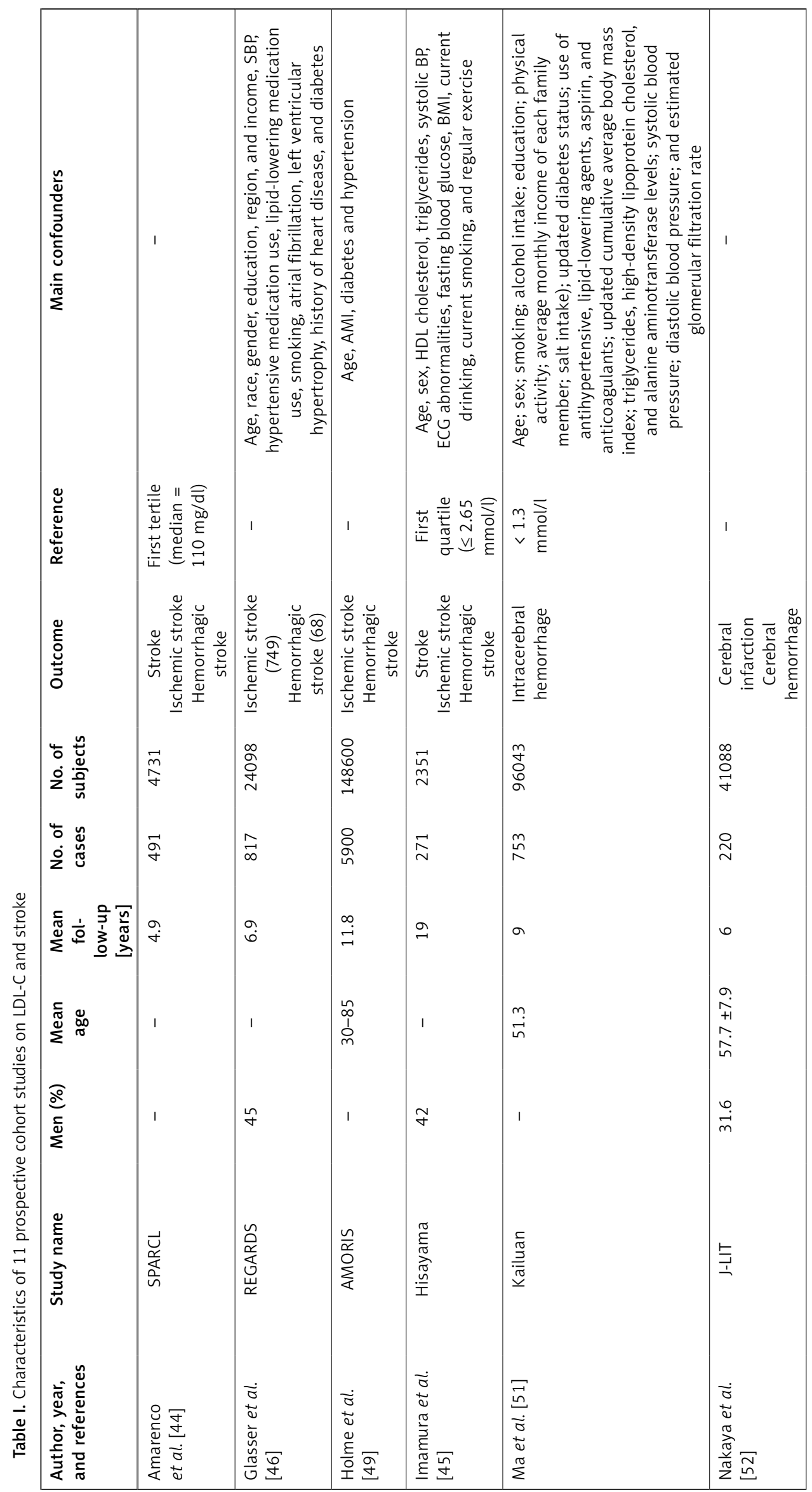


M. Banach, N. Shekoohi, D.P. Mikhailidis, G.Y.H. Lip, A.V. Hernandez, M. Mazidi, on behalf of the Lipid and Blood Pressure Meta-analysis Collaboration (LBPMC) Group and the International Lipid Expert Panel (ILEP)

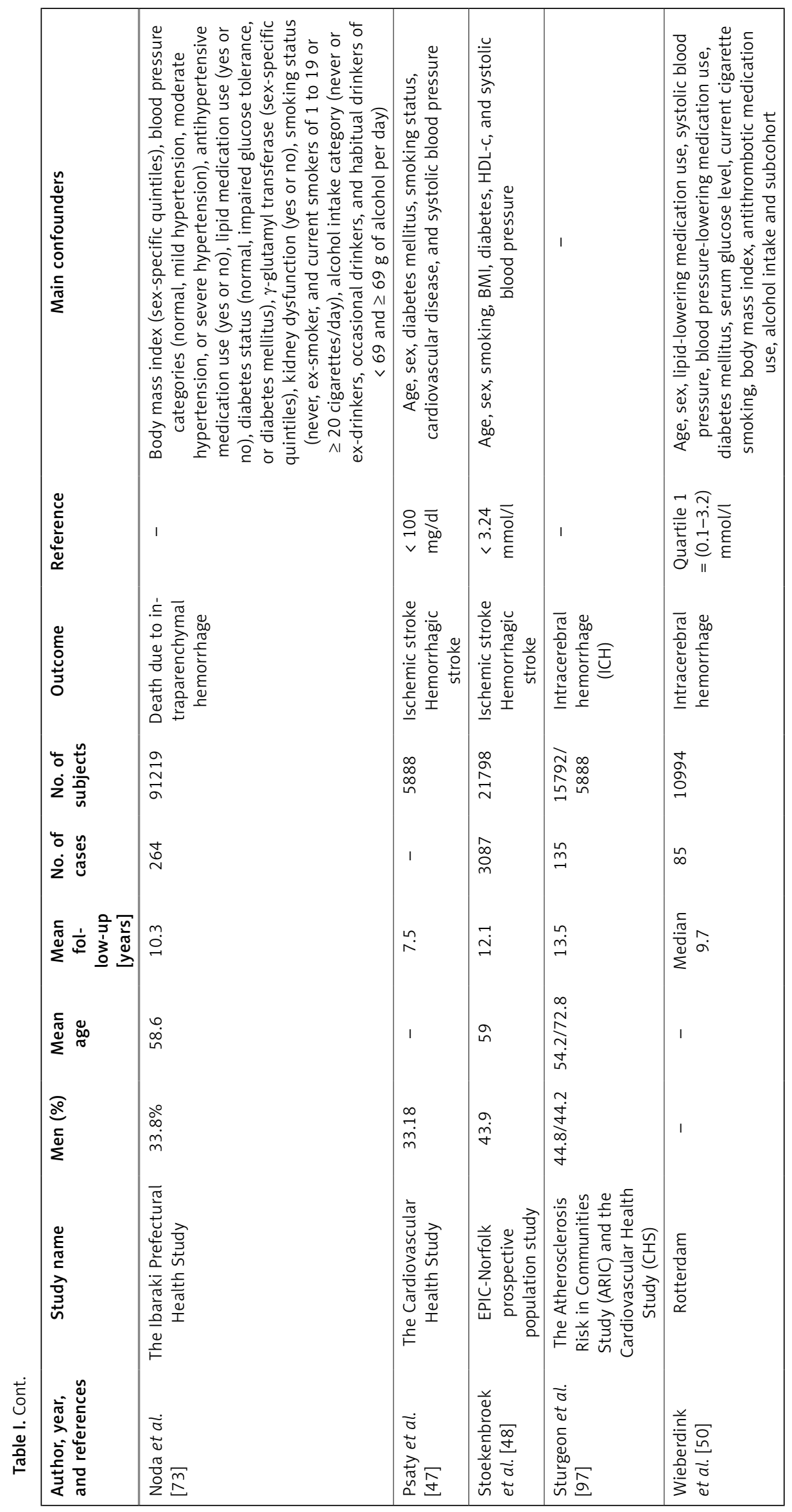




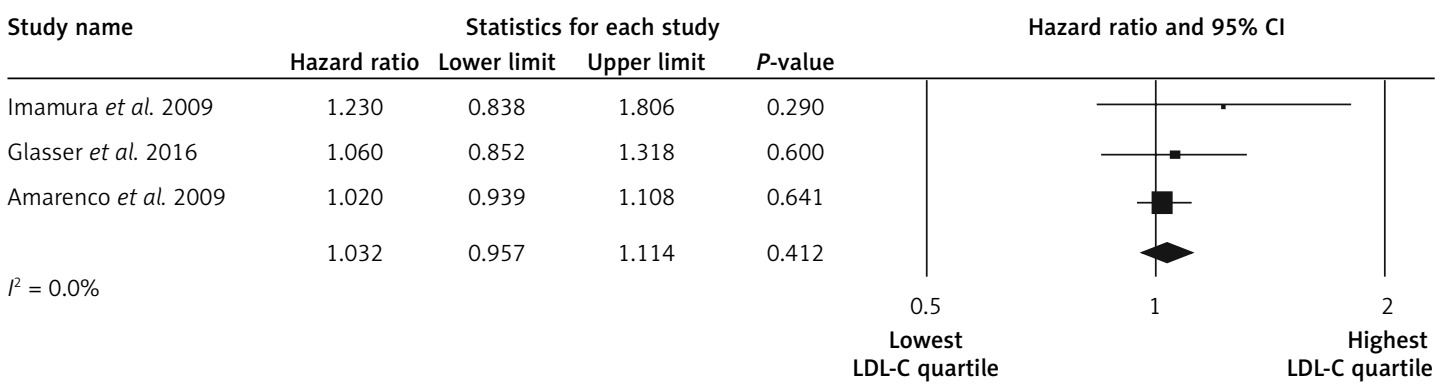

Figure 2. Forest plot of impact of LDL-C on stroke events

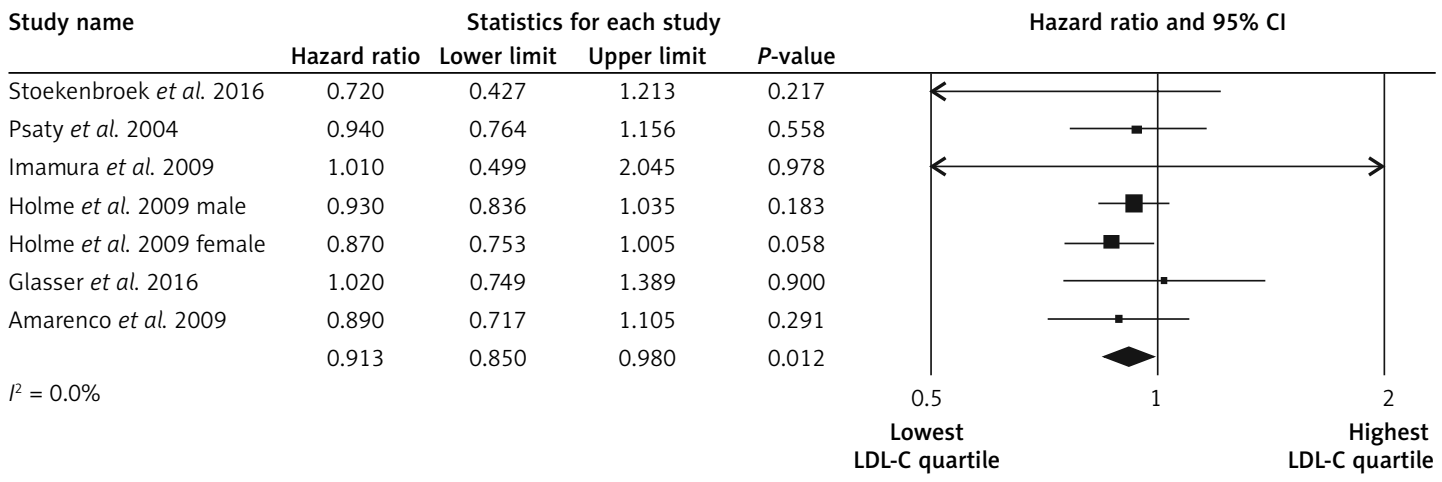

Figure 3. Forest plot of impact of LDL-C on hemorrhagic stroke events

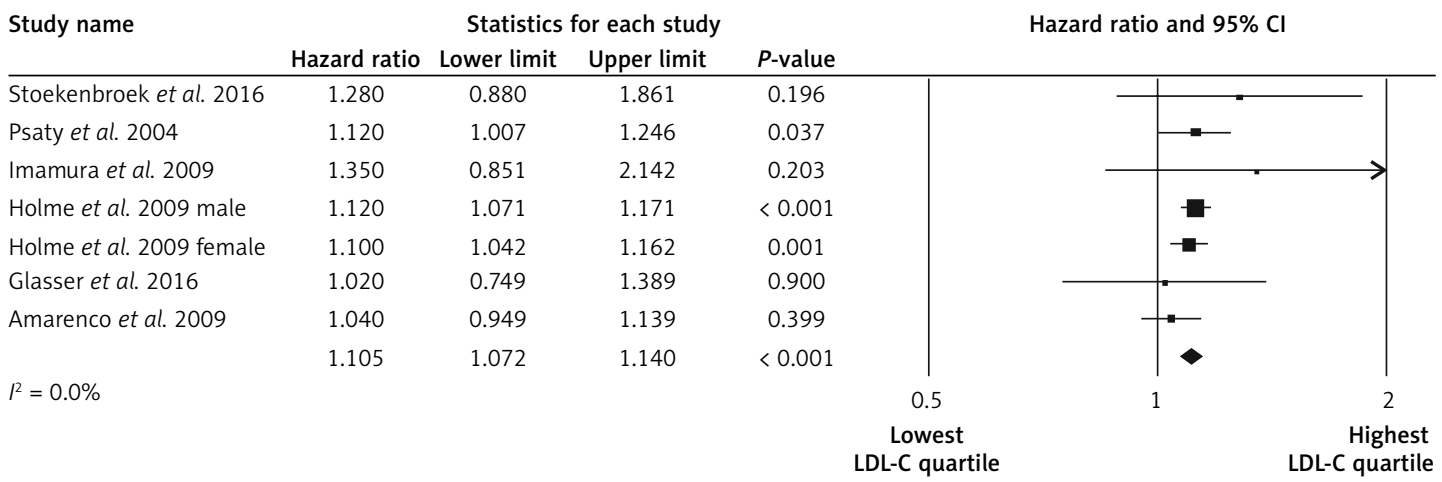

Figure 4. Forest plot of impact of LDL-C on ischemic stroke events

further evaluation, of which 18 RCTs with 165,988 participants were included in the meta-analysis.

\section{Characteristics of included trials}

A summary of trial characteristics is presented in Table II. The included trials were published between 2002 [53] and 2018 [32] and were performed in the United States of America (one study) [54], the UK (one study) [27] and Italy (one study) [55]. The other 15 studies were multicenter $[29,30,32,33,53,56-64]$. The number of study participants ranged from 2107 [56] to 27,564 [33]. The proportion of men in the studies ranged from $48.3 \%$ [29] to $82.2 \%$ [54]. The mean age (63.1 years) of participants ranged from 49.7 [56] to 75.3 [55] years. The follow-up duration from the baseline to endpoint across studies was from 2.2 year [33] to 6 years [64]) (mean follow-up was 4.1 years). Baseline and achieved LDL-C level were assessed. Baseline LDL-C level ranged from 2.25 [32] to $4.1(\mathrm{mmol} / \mathrm{l})$ [56], and the range of achieved LDL-C level was from 0.78 [33] to 3.1 ( $\mathrm{mmol} / \mathrm{l})$ [56].

\section{Risk of bias assessment}

There was unclear risk of bias in some of the items including allocation concealment, blinding of participants and personnel. All of the evaluated studies had a low risk of bias according to selective outcome reporting. None of the studies had an item with high risk of bias. Details of the quality of bias assessment are shown in Supplementary Table SIV.

\section{Meta-analysis of the effect of lipid-lowering agents on all strokes}

For those who achieved an LDL-C level $\leq 1.3$ $\mathrm{mmol} / \mathrm{l}(50 \mathrm{mg} / \mathrm{dl})$, the RR of the effect of LLAs on all strokes was $0.81,95 \% \mathrm{Cl}$ : 0.73-0.91, $p<0.001$, 


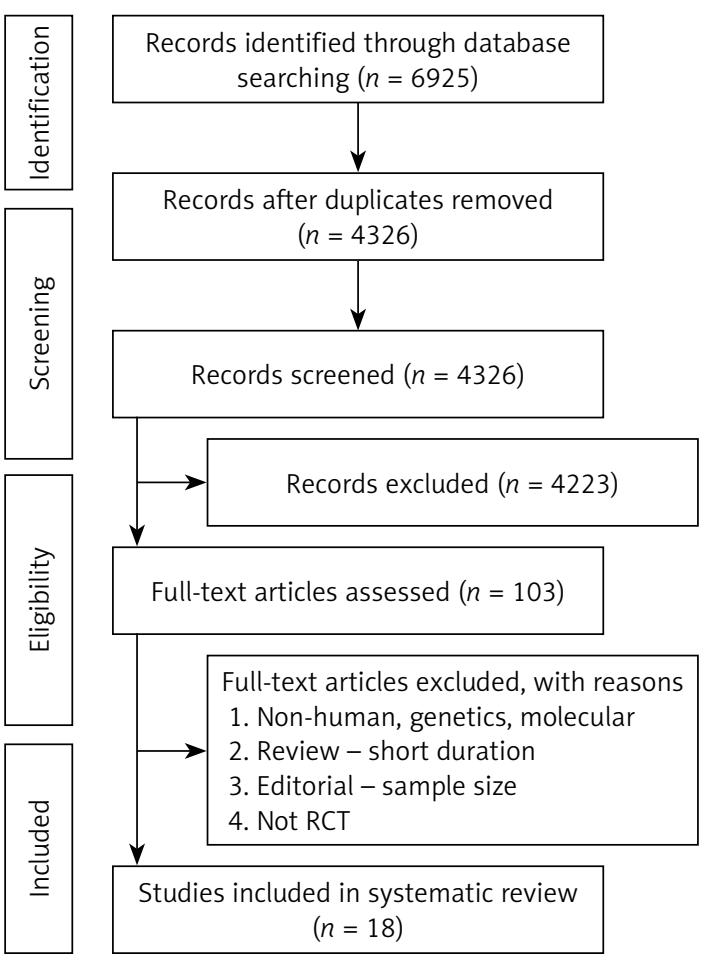

Figure 5. PRISMA flow chart for the selection of RCTs

$\mathrm{ARR}=0.4 \%$, NNT $=250$, heterogeneity $p=0.273$ $R^{2}=27 \%, n=3$ studies; TSA for this group indicates that the optimal sample size was reached, so a difference of $35 \%$ between groups is firmly discarded and no further studies are required. For those who achieved LDL-C between $1.3 \mathrm{mmol} / \mathrm{l}$ $(50 \mathrm{mg} / \mathrm{dl})$ and $<1.8 \mathrm{mmol} / \mathrm{l}(70 \mathrm{mg} / \mathrm{dl})$ the RR of the effect of LLAs on all strokes was $0.83,95 \% \mathrm{Cl}$ : $0.59-1.17, p=0.299, \mathrm{ARR}=0.7 \%$, NNT $=143$, heterogeneity $p=0.025 ; l^{2}=72 \%, n=3$ studies; TSA indicated that no boundaries were reached, implying that further studies are needed. For those at $\geq 1.8 \mathrm{mmol} / \mathrm{l}(70 \mathrm{mg} / \mathrm{dl})$ the RR of the effect of LLAs on all strokes was $0.88,95 \% \mathrm{Cl}$ : $0.80-0.96$, $p=0.008, \mathrm{ARR}=0.7 \%$, NNT $=143$, heterogeneity $p=0.013 ; l^{2}=53 \%, n=13$ studies, Figure 6). TSA indicated that both benefit boundaries and optimal sample size were reached and our conclusion is robust; the TSA finding was robust even with $\mathrm{RRR}=20 \%$.

After grouping the patients according to those on statin therapy vs. non-statin therapy, for those on statin therapy the RR for all strokes was 0.88 , 95\% Cl: 0.80-0.97, $p=0.011, \mathrm{ARR}=0.6 \%$, NNT = $167, n=15$ studies, Figure 7), heterogeneity $p=$ $0.004 ; l^{2}=56 \%$ ), TSA indicated that both benefit boundaries and optimal sample size were reached and our conclusion is robust (the TSA finding was robust even with RRR $=20 \%$ ). For those on non-statin therapy the pooled estimate (RR) for all strokes was 0.81 (95\% Cl: 0.74-0.89, $p<0.001$,
$\mathrm{ARR}=0.5 \%, \mathrm{NNT}=200$, heterogeneity $p=0.431$; $R^{2}=0.0 \%, n=4$ studies). TSA indicated that both benefit boundaries and optimal sample size were reached and our conclusion is robust (the TSA finding was robust even with RRR $=20 \%$ ).

For those at primary prevention, the pooled estimate (RR) of the effect of lipid-lowering agents on all strokes was $0.85(95 \% \mathrm{Cl}$ : 0.78-0.93, $p<0.001, \mathrm{ARR}=0.6 \%$, NNT $=167$, heterogeneity $p=0.006 ; I^{2}=52.7 \%, n=17$ studies, Figure 8). TSA indicated that both benefit boundaries and optimal sample size were reached and our conclusion is robust (the TSA finding was robust even with $R R R=20 \%$ ). For those at secondary prevention the pooled estimate (RR) of the effect of lipid-lowering agents on all strokes was 0.90 (95\% Cl: 0.79-1.01, $p=0.092, \operatorname{ARR}=1.2 \%, \mathrm{NNT}=83$, heterogeneity $p=0.250 ; l^{2}=24.5 \%, n=2$ studies). TSA for this group indicates that the optimal sample size was reached, so a difference of $35 \%$ between groups is firmly discarded and no further studies are required

\section{Meta-analysis of the effect of lipid-lowering} agents on ischemic strokes

For those who achieved LDL-C level $\leq 1.3 \mathrm{mmol} / \mathrm{l}$, the pooled estimate (RR) of the effect of lipid-lowering agents on ischemic stroke was 0.78 (95\% Cl: 0.69-0.88, ARR $=0.5 \%$, NNT $=200$, heterogeneity $p=0.589 ; l^{2}=0.0 \%, n=3$ studies), TSA indicated that the optimal sample size was reached and our conclusion is robust (the TSA finding was robust even with RRR $=20 \%$ ). For those at $1.3 \mathrm{mmol} / \mathrm{l}(50 \mathrm{mg} / \mathrm{dl})$ to $1.8 \mathrm{mmol} / \mathrm{l}$ $(70 \mathrm{mg} / \mathrm{dl})$ the pooled estimate (RR) of the effect of lipid-lowering agents on ischemic stroke was 0.76 (95\% Cl: $0.54-1.05, p=0.104$, ARR $=0.8 \%$, NNT $=125$, heterogeneity $p=0.099 ; R^{2}=56.7 \%$, $n=3$ studies), TSA indicated that benefit boundaries were reached and our conclusion is robust. For those at $\geq 1.8 \mathrm{mmol} / \mathrm{l}(70 \mathrm{mg} / \mathrm{dl})$, the pooled estimate (RR) of the effect of lipid-lowering agents on ischemic stroke was $0.75(95 \% \mathrm{Cl}$ : $0.67-0.83$, $p<0.001, \mathrm{ARR}=1.3 \%$, NNT $=77$, heterogeneity $p=0.423 ; r^{2}=0.0 \%, n=4$ studies). TSA indicated that both benefit boundaries and optimal sample size were reached and our conclusion is robust (the TSA finding was robust even with RRR $=20 \%$ ).

We divided people into statin therapy vs. non-statin therapy; for those on statin therapy the pooled estimate (RR) of ischemic stroke was 0.76 (95\% Cl: $0.69-0.84, p<0.001$, ARR $=1.3 \%$, NNT $=77$, heterogeneity $p=0.201 ; l^{2}=32 \%, n=6$ studies). TSA indicated that both benefit boundaries and optimal sample size were reached and our conclusion is robust (the TSA finding was robust even with RRR $=20 \%$ ). For those on non-statin therapy the pooled estimate (RR) of ischemic 
Relationship between low-density lipoprotein cholesterol, lipid-lowering agents and risk of stroke: a meta-analysis of observational studies $(n=355,591)$ and randomized controlled trials $(n=165,988)$

Table II. Characteristics of included trials on lipid-lowering agents and stroke

\begin{tabular}{|c|c|c|c|c|c|c|c|}
\hline $\begin{array}{l}\text { Author and } \\
\text { references }\end{array}$ & $\begin{array}{l}\text { Study name, year of } \\
\text { publication, country } \\
\text { of origin }\end{array}$ & $\begin{array}{c}\text { Men } \\
(\%)\end{array}$ & $\begin{array}{l}\text { Mean } \\
\text { age }\end{array}$ & $\begin{array}{l}\text { Mean } \\
\text { follow-up } \\
\text { [years] }\end{array}$ & $\begin{array}{l}\text { Number of } \\
\text { participants }\end{array}$ & $\begin{array}{l}\text { Baseline } \\
\text { LDL choles- } \\
\text { terol level } \\
\text { [mmol/l] }\end{array}$ & $\begin{array}{l}\text { Achieved } \\
\text { LDL choles- } \\
\text { terol level } \\
\text { [mmol/l] }\end{array}$ \\
\hline $\begin{array}{l}\text { Furberg C } \\
\text { et al. [53] }\end{array}$ & $\begin{array}{l}\text { ALLHAT-LLT, 2002, } \\
\text { multicenter }\end{array}$ & 51.1 & 66.3 & 4.8 & 10355 & 3.77 & 2.87 \\
\hline $\begin{array}{l}\text { HPS } \\
\text { (Cohort 1) } \\
{[27]}\end{array}$ & $\operatorname{HPS}(p), 2002$, UK & - & - & 5 & 17256 & - & 2.3 \\
\hline $\begin{array}{l}\text { HPS } \\
\text { (Cohort 2) } \\
{[27]}\end{array}$ & HPS(s), 2002, UK & - & - & 4.8 & 3280 & - & 2.4 \\
\hline $\begin{array}{l}\text { Shepherd J } \\
\text { et al. [29] }\end{array}$ & $\begin{array}{l}\text { PROSPER, 2002, } \\
\text { multicenter }\end{array}$ & 48.3 & 75.3 & 3.2 & 5804 & 3.8 & 2.5 \\
\hline $\begin{array}{l}\text { Holdaas H } \\
\text { et al. [56] }\end{array}$ & $\begin{array}{l}\text { ALERT, 2003, } \\
\text { multicenter }\end{array}$ & 66 & 49.7 & 5.1 & 2107 & 4.1 & 3.1 \\
\hline $\begin{array}{l}\text { Sever PS } \\
\text { et al. [30] }\end{array}$ & $\begin{array}{l}\text { ASCOT-LLA, 2003, } \\
\text { multicenter }\end{array}$ & 81.1 & 63.1 & 3.3 & 10305 & 3.4 & 2.21 \\
\hline $\begin{array}{l}\text { Koren MJ } \\
\text { et al. [54] }\end{array}$ & $\begin{array}{l}\text { ALLIANCE, 2004, } \\
\text { centers in US }\end{array}$ & 82.2 & 61.1 & 4.3 & 2442 & 3.81 & 2.46 \\
\hline $\begin{array}{l}\text { Colhoun } \\
\text { HM et al. } \\
{[103]}\end{array}$ & $\begin{array}{c}\text { CARDS, 2004, Ireland, } \\
\text { UK }\end{array}$ & 68 & 61.6 & 3.9 & 2838 & 3.04 & 1.75 \\
\hline $\begin{array}{l}\text { Pedersen } \\
\text { TR et al. } \\
{[57]}\end{array}$ & $\begin{array}{l}\text { IDEAL, 2005, } \\
\text { multicenter }\end{array}$ & 80.8 & 61.6 & 4.8 & 8888 & 3.15 & 2.01 \\
\hline $\begin{array}{l}\text { LaRosa JC } \\
\text { et al. [58] }\end{array}$ & $\begin{array}{l}\text { TNT, } 2005 \text {, } \\
\text { multicenter }\end{array}$ & 81 & 61 & 4.9 & 10001 & 2.51 & 1.99 \\
\hline $\begin{array}{l}\text { Knopp RH } \\
\text { et al. [59] }\end{array}$ & $\begin{array}{l}\text { ASPEN, 2006, } \\
\text { multicenter }\end{array}$ & 66.3 & 61 & 4 & 2410 & 2.93 & 2.04 \\
\hline $\begin{array}{l}\text { Amarenco } \\
\text { P et al. [60] }\end{array}$ & $\begin{array}{l}\text { SPARCL(s), 2006, } \\
\text { multicenter }\end{array}$ & 59.6 & 62.7 & 4.9 & 4731 & 3.44 & 1.89 \\
\hline $\begin{array}{l}\text { Ridker PM } \\
\text { et al. [61] }\end{array}$ & $\begin{array}{l}\text { CORONA, 2007, } \\
\text { multicenter }\end{array}$ & 76.4 & 73 & 2.7 & 5011 & 3.54 & 1.97 \\
\hline $\begin{array}{l}\text { Tavazzi L } \\
\text { et al. [55] }\end{array}$ & $\begin{array}{l}\text { GISSI-HF, 2008, } \\
\text { centers in Italy }\end{array}$ & 77.4 & 68 & 3.9 & 4574 & 3.16 & 2.15 \\
\hline $\begin{array}{l}\text { Fellström } \\
\text { BC et al. } \\
{[62]}\end{array}$ & $\begin{array}{l}\text { AURORA, 2009, } \\
\text { multicenter }\end{array}$ & 62.1 & 64.1 & 3.2 & 2773 & 2.59 & 1.5 \\
\hline $\begin{array}{l}\text { Baigent C } \\
\text { et al. [63] }\end{array}$ & $\begin{array}{l}\text { SHARP, } 2011 \text {, } \\
\text { multicenter }\end{array}$ & 62.5 & 62 & 4.9 & 9270 & 2.77 & 1.69 \\
\hline $\begin{array}{l}\text { Cannon CP } \\
\text { et al. }[64]\end{array}$ & $\begin{array}{l}\text { IMPROVE-IT(p), 2015, } \\
\text { multicenter }\end{array}$ & - & - & 6 & 17455 & 2.46 & 1.30 \\
\hline $\begin{array}{l}\text { Sabatine } \\
\text { MS et al. } \\
{[33]}\end{array}$ & $\begin{array}{l}\text { FOURIER, 2017, } \\
\text { multicenter }\end{array}$ & 75.4 & 62.5 & 2.2 & 27564 & 2.4 & 0.78 \\
\hline $\begin{array}{l}\text { Schwartz } \\
\text { GG et al. } \\
{[32]}\end{array}$ & $\begin{array}{l}\text { ODYSSEY OUTCOMES, } \\
\text { 2018, multicenter }\end{array}$ & 74.8 & 58 & 2.8 & 18924 & 2.25 & 0.97 \\
\hline
\end{tabular}

stroke was 0.77 (95\% Cl: 0.69-0.85, $p<0.001$ $\mathrm{ARR}=0.5 \%$, NNT $=200$, heterogeneity $p=0.694$; $R^{2}=0.0 \%, n=4$ studies). TSA indicated that both benefit boundaries and optimal sample size were reached and our conclusion is robust (the TSA finding was robust even with $R R R=20 \%$ ).
Meta-analysis of the effect of lipid-lowering agents on hemorrhagic strokes

For those who achieved LDL-C level $\leq 1.3 \mathrm{mmol} / \mathrm{l}$ $(50 \mathrm{mg} / \mathrm{dl})$, the pooled estimate (RR) of the effect of lipid-lowering agents on hemorrhagic stroke was 1.14 (95\% Cl: 0.84-1.54, heteroge- 
M. Banach, N. Shekoohi, D.P. Mikhailidis, G.Y.H. Lip, A.V. Hernandez, M. Mazidi, on behalf of the Lipid and Blood Pressure Meta-analysis Collaboration (LBPMC) Group and the International Lipid Expert Panel (ILEP)

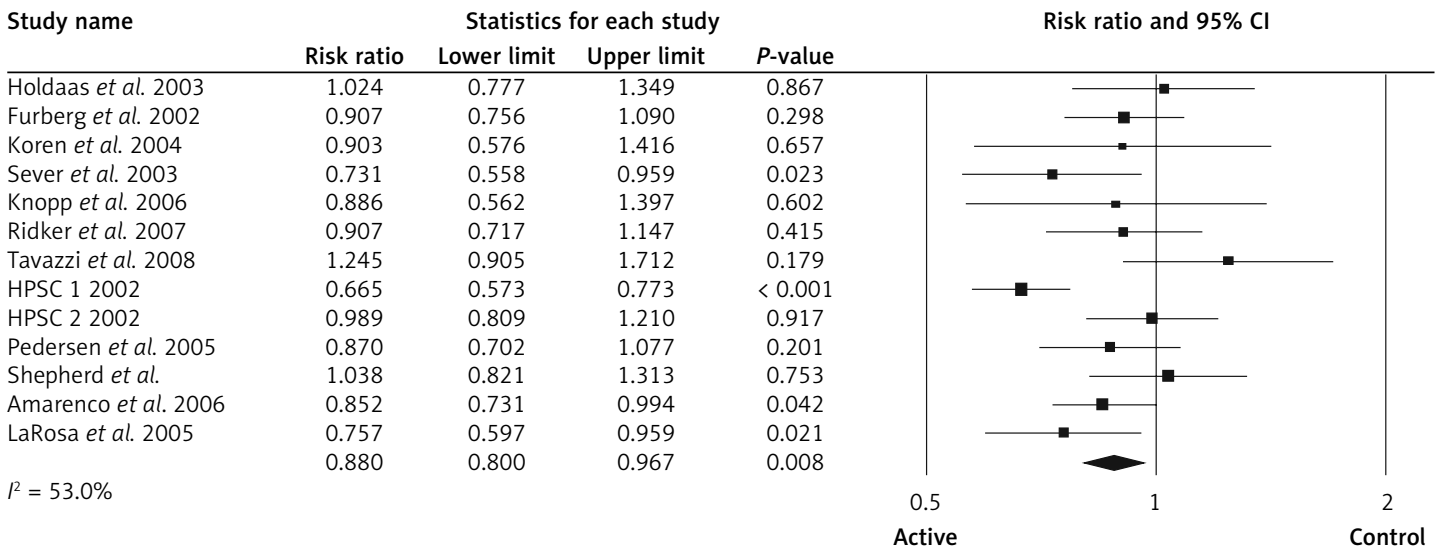

Figure 6. Forest plot of impact of lipid-lowering agents on all strokes (those at $\geq 1.8 \mathrm{mmol} / \mathrm{l}$ )

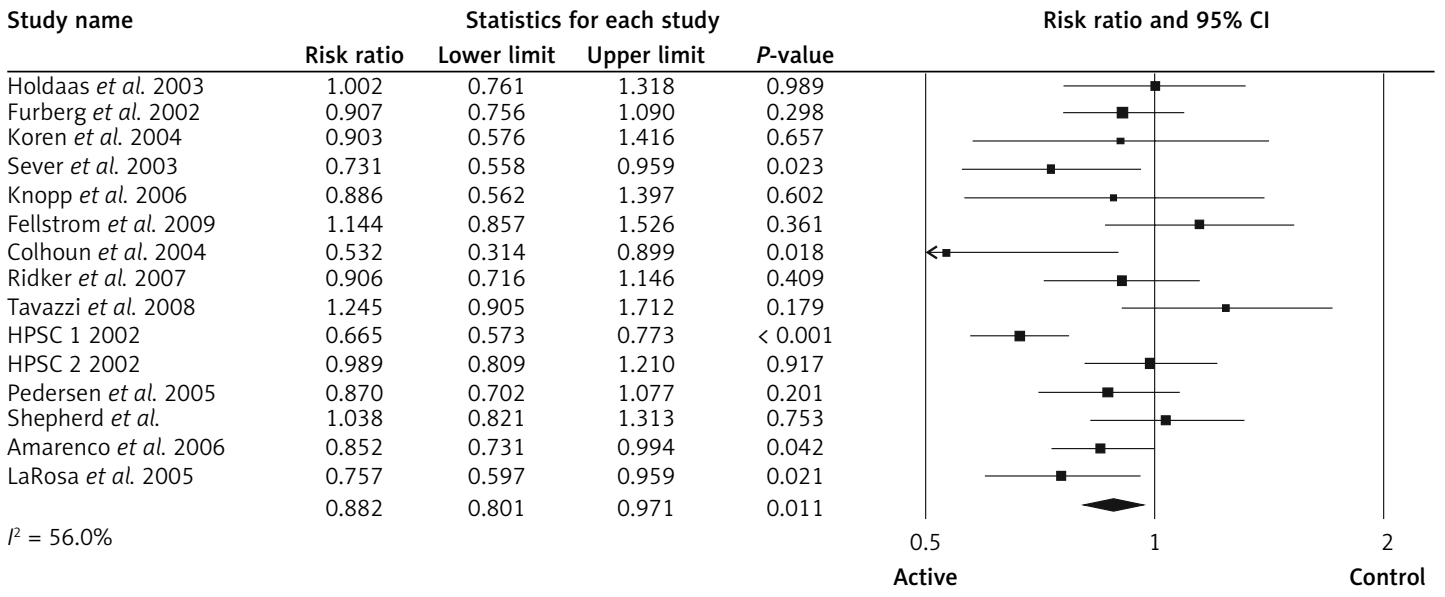

Figure 7. Forest plot of impact of statin therapy on all strokes

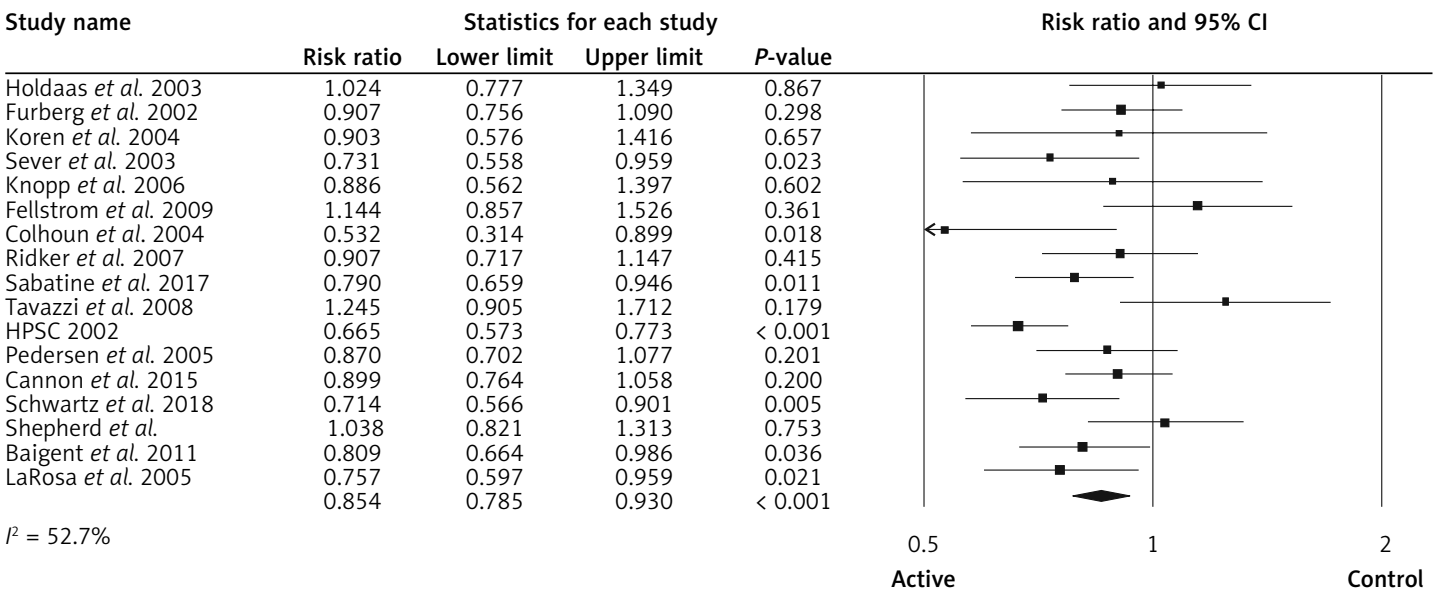

Figure 8. Forest plot of impact of lipid-lowering agents on all strokes (those at primary prevention)

neity $p=0.170 ; R^{2}=43.6 \%, n=3$ studies), and TSA indicated that no boundaries were reached; thus further studies are needed. For those at $1.3 \mathrm{mmol} / \mathrm{l}(50 \mathrm{mg} / \mathrm{dl})$ to $1.8 \mathrm{mmol} / \mathrm{l}(70 \mathrm{mg} / \mathrm{dl})$ the pooled estimate (RR) of the effect of lipid-lowering agents on hemorrhagic stroke was 1.20 (95\% Cl: $0.84-1.69, p=0.301, n=2$ studies), heterogeneity $\left.p=0.960 ; p^{2}=0.0 \%\right)$, and TSA indicated that no boundaries were reached; thus further studies are needed. For those at $\geq 1.8 \mathrm{mmol} / \mathrm{l}(70 \mathrm{mg} / \mathrm{dl})$, the pooled estimate (RR) of the effect of lipid-lowering agents on hemorrhagic stroke was 1.25 (95\% Cl: $0.82-1.88(p=0.289)$, heterogeneity $p=0.050$; $R^{2}=57.9 \%, n=5$ studies). TSA indicated that no boundaries were reached, so further studies are needed. 
For those on statin therapy the pooled estimate (RR) of the effect of lipid-lowering agents on hemorrhagic stroke was 1.23 (95\% Cl: 0.88-1.71, $p=0.219, n=6$ studies), heterogeneity $p=0.090$ $\left.P^{2}=47.4 \%\right) ;$ TSA for this group indicates that the futility boundary was reached, so a difference of $35 \%$ between groups is firmly discarded and no further studies are required. For those on combination therapy the pooled estimate (RR) of the effect of lipid-lowering agents on hemorrhagic stroke 1.16 (95\% Cl: 0.90-1.48 ( $p=0.232)$, heterogeneity $p=0.309 ; l^{2}=16.5 \%, n=4$ studies). TSA for this group indicates that the futility boundary was reached, so a difference of $35 \%$ between groups is firmly discarded and no further studies are required.

\section{Discussion}

Our study sheds light on the debatable association between low LDL-C and different type of strokes. According to our results regarding the effect of LDL on the risk of stroke, there was a non-significant trend towards higher risk of hemorrhagic stroke for all investigated LDL-C levels (besides the highest LDL levels in cohort studies analyses), and higher LDL-C level (> $70 \mathrm{mg} / \mathrm{dl}$ ) was associated with significantly higher risk of ischemic stroke. The analysis also confirmed a large effect of statin and non-statin lipid-lowering therapy on all strokes and ischemic strokes but without a significant effect on hemorrhagic strokes. This information can help to determine the optimal LDL-C range for stroke prevention and help to plan future studies with LLAs and different LDL-C targets. Further, well-designed studies are still needed to assess the effects of LLAs on hemorrhagic stroke. However, our data do not indicate any significant association between LDL-C thresholds and different lipid-lowering therapies and the risk of hemorrhagic stroke (only a numerical increase).

Hypercholesterolemia is associated with atherosclerosis due to the elevated concentration of oxidized or modified LDL-C leading to endothelial dysfunction [65]. Most of the epidemiological studies have reported an association between higher cholesterol level and an increased risk of ischemic stroke [8, 66-69]. On the other hand, given that cholesterol plays an important role in the structure formation of cell membranes, low cholesterol can be a potential risk factor for intracranial hemorrhage $(\mathrm{ICH})$ [70]. It was found that a low level of cholesterol can lead to weakened endothelium, which results in arterial fragility and hemorrhage [70, 71]. It should be noted that weakened endothelium may be more susceptible to microaneurysms, which are one of the major pathological results of cerebral hemorrhage [71].
Some epidemiological studies demonstrated an inverse relationship between $\mathrm{LDL}-\mathrm{C}$ levels and risk of ICH $[72,73]$, which was not definitely confirmed in our analysis. There might be other plausible mechanisms with regard to the potential association between low LDL-C level and increased risk of hemorrhagic stroke. Erythrocyte fragility can result from low cholesterol in erythrocyte membrane [74], LDL-related platelet activation and tissue factor expression [75] and impaired coagulation function [76]. Furthermore, microbleeds, as a risk factor for $\mathrm{ICH}$, can be increased by low LDL-C concentration [77].

It is widely known that stroke is one of the major complications of cardiovascular disease (CVD). The association between LDL-C and each of these different types is likely to differ, as well as the link between different lipid-lowering therapies (statin vs. non-statin) and different types of stroke. Several prospective studies have evaluated the relationship between $L D L-C$ and stroke, but the results are inconsistent. In a meta-analysis of data from 170,000 participants in 26 randomized trials, risk of hemorrhagic stroke was not increased by reduction in the LDL-C level with statins [78]; however, a non-significant increase in the incidence of hemorrhagic stroke by statins was reported [79]. Statin therapy for the secondary stroke prevention population was associated with higher risk of hemorrhagic stroke [79]. In addition, a meta-analysis of 23 randomized trials reported that each $1 \mathrm{mmol} / \mathrm{l}$ decrease in the achieved LDL-C level was associated with a $23.5 \%$ significant reduction in total stroke risk, whereas the risk of hemorrhagic stroke was not significantly increased by a lower achieved LDL-C level [80] - similar results are in fact observed also in our analyses.

The Stroke Prevention by Aggressive Reduction in Cholesterol Levels (SPARCL) trial with 4731 participants after 4.9 years of follow-up showed that baseline LDL-C was not predictive for stroke. Only baseline HDL-C and LDL/HDL ratio were attributed with an outcome of ischemic stroke [81]. In accordance with this study, the Perindopril Protection Against Recurrent Stroke (PROGRESS) trial found no association between baseline LDL-C and risk of recurrent stroke [82]. In a cohort study of 23,367 participants with a mean follow-up of $7.5 \pm 2.9$ years and 1031 strokes (814 ischemic, 77 hemorrhagic), LDL-C was significantly associated with increased risk of ischemic stroke by $8 \%$ [83]. In a meta-regression analysis from 49 trials including 312,175 participants (mean age: 62 years, 24\% women) with approximately 4000 major vascular events during a mean of 4.3 years, lower achieved LDL-C level was significantly associated with lower rate of major coronary events (including coronary death and $\mathrm{MI}$ ) for primary and secondary preven- 
M. Banach, N. Shekoohi, D.P. Mikhailidis, G.Y.H. Lip, A.V. Hernandez, M. Mazidi, on behalf of the Lipid and Blood Pressure Meta-analysis Collaboration (LBPMC) Group and the International Lipid Expert Panel (ILEP)

tion trials [84]. Moreover, no significant association was reported between LDL-C and ischemic stroke in the Atherosclerosis Risk in Communities Study (ARIC) [7] and Framingham Study [85], and between LDL-C and hemorrhagic stroke $[86,87]$. However, some limitations of these studies should be borne in mind, such as the relatively short follow-up (1-6 years) and small number of cases of hemorrhagic stroke. Moreover, in the Hisayama population-based study, with 2351 participants (271 strokes) followed up for 19 years, the authors reported no significant association between LDL-C concentration and stroke risk [15]. Most of the available clinical trials - including Pravastatin or Atorvastatin Evaluation and Infection Therapy (PROVE-IT), Reversal of Atherosclerosis with Aggressive Lipid Lowering (REVERSAL), a Study to Evaluate the Effect of Rosuvastatin on Intravascular Ultrasound Derived Coronary Atheroma Burden (ASTEROID), and Justification for the Use of Statins in Prevention: An Intervention Trial Evaluating Rosuvastatin (JUPITER) - reported that LDL-C lower than $70 \mathrm{mg} / \mathrm{dl}$ reversed the development of atherosclerotic plaque and reduced heart attack and all stroke rates [88-91]. In a meta-analysis of non-statin clinical trials, no significant positive association between LDL-C lowering and increased risk of hemorrhagic stroke was reported [24]. Finally, a nationwide cohort study of 52,421 hypercholesterolemic patients treated with open-labeled simvastatin for 6 years also reported no association between cerebral hemorrhage and serum lipid concentrations [92]. Our results are in line with the above-mentioned results, finding no significant association between LDL-C levels and the risk of stroke, although a non-significant positive trend was observed for this association, interestingly numerically the lowest for the LDL-C $<50 \mathrm{mg} / \mathrm{dl}(\mathrm{RR}=1.14)$ and the largest for LDL-C $\geq 70 \mathrm{mg} / \mathrm{dl}(\mathrm{RR}=1.25)$.

A prospective population-based cohort study with 9068 participants (age $\geq 55$ years) during a mean follow-up of 9.7 years reported no association between LDL-C and intracerebral hemorrhage [93]. However, $36 \%$ of strokes were classified as unspecific because neuroimaging had not been performed, and the presence of residual confounding due to unmeasured determinants influenced the results of the study. A large multicenter, prospective population-based study with 5201 participants age 65 and older (mean follow-up: 7.5 years) reported a marginally significant association between LDL-C and ischemic stroke, and no association between LDL-C and hemorrhag ic stroke. The authors demonstrated that lipid measure could not be important predicators of the outcomes of $\mathrm{MI}$, ischemic stroke, hemorrhage stroke and total mortality [94]. The analysis of
21,798 participants of the European Prospective Investigation into Cancer in Norfolk (EPICNORFOLK) population study showed substantial heterogeneity in the association between the traditional atherosclerosis risk factors. The authors reported that LDL-C was a particularly strong risk factor for CAD, but it was less strongly associated with ischemic and hemorrhagic stroke [95]. They also reported that different associations between $L D L$ and CAD vs. ischemic stroke were due to the morphological differences in plaques between intra- and extracranial arteries [96]. Interestingly, in a pooled cohort of the ARIC study $(15,792$ men and women, aged 45-64 years) and the Cardiovascular Heart Study (5888 men and women, aged 65 or over) the authors reported an inverse association between LDL-C and incident ICH [97]. Furthermore, a significant inverse association between LDL-C and hemorrhagic stroke was found in the Framingham Study [85]. Finally, a cohort study that included 96,043 participants (mean age: 51.3 years) with 9 years of follow-up reported that lower LDL-C concentration (LDL-C $<70 \mathrm{mg} / \mathrm{dl}$ ) was significantly associated with higher risk of intracerebral hemorrhage, and this association became non-significant with LDL-C $\geq 70 \mathrm{mg} / \mathrm{dl}$ [51]. Moreover, a large population-based prospective study that included 91,219 participants (40-79 years of age, 30,802 men, 60,417 women) for 10.3 years showed a significant association between low LDL-C levels and increased risk of death due to intraparenchymal hemorrhage [73]. Similar results were observed in a pooled prospective cohort study that included 21,630 individuals with 135 cases of incident ICH, which showed that lower LDL-C was associated with higher risk of ICH [97]. Our results do not confirm any significant association between LDL levels ( $<$ and $\geq 70 \mathrm{mg} / \mathrm{dl}$ ) and the risk of hemorrhagic stroke and significant reduction of ischemic strokes for all investigated achieved LDL-C levels.

We also found no significant effect of lipid-lowering agents regardless of the types (statin and non-statin therapy) and achieved level of LDL-C on the risk of hemorrhagic stroke. There are several studies available with regard to the effect of lipid-lowering agents on the risk of stroke. Statin therapy was effective in reducing CV events including stroke according to the degree of LDL-C level lowering $[32,33,64]$. With regard to the association between lowering LDL-C and relative $\mathrm{CV}$ risk reduction in statin and non-statin groups, a meta-regression study that included 312,175 individuals of 49 trials (mean age: 62 years, 20\% women) reported that statin and non-statin therapies were associated with lower achieved LDL-C levels. Moreover, a significant linear association between achieved LDL-C and the rate of cardio- 
vascular outcomes (including stroke) was found [84]. Similar to our findings, a prospective metaanalysis that included 90,056 individuals in 14 randomized trials of statin reported that risk of major coronary events, coronary revascularization and stroke was reduced by statin therapy by about one fifth per $\mathrm{mmol} / \mathrm{I}$ in LDL cholesterol during 5-year follow-up [98]. The SPARCL trial reported that a lipid-lowering agent (atorvastatin $80 \mathrm{mg} /$ day) significantly reduced the risk of recurrent stroke regardless of baseline LDL-C and other lipid parameters [99]. Similarly to our results, an insignificant association between statin therapy and the risk of hemorrhagic stroke was observed in the Cholesterol Treatment Trialists' (CTT) meta-analysis of statin clinical trials [23]. The effectiveness of ezetimibe with simvastatin therapy in order to prevent stroke and other adverse cardiovascular events was assessed in the Improved Reduction of Outcomes: Vytorin Efficacy International Trial (IMPROVE-IT), which was a multinational trial of 18,144 patients, of whom 641 (3.5\%) experienced at least 1 stroke, and most were ischemic $(n=527$ $(82 \%))$. They found a non-significant reduction in the first event of stroke of any type with ezetimibe plus simvastatin compared to simvastatin monotherapy. Ischemic stroke was significantly reduced by adding ezetimibe to simvastatin. However, no significant increase in hemorrhagic stroke was observed in statin therapy with ezetimibe [100]. A meta-analysis involving data from the analysis of 4405 patients who completed phase 2 or 3 studies of evolocumab during 1 year, and a randomized trial on alirocumab including 2341 patients during 1.5 years follow-up reported no significant effect of PCSK9 inhibition on stroke rate. The number of ischemic strokes was small in both trials, and no hemorrhagic stroke was reported in either study [101]. Moreover, an animal study showed that PCSK9 ${ }^{-1-}$ mice had lower LDL-C, high-density lipoprotein cholesterol, and total cholesterol levels that PCSK9 ${ }^{+/+}$mice before and after 1 month on the high-fat/high-cholesterol diet. They found that hemorrhagic complications after acute ischemic stroke should not be increased by PCSK9 inhibition which leads to LDL-C lowering [102, 103]. The subject is still debatable, and the most recent results also give opposite results for extremely and very low LDL-C and the risk of hemorrhagic stroke and the role of lipid-lowering therapies, mainly statins, in this association [104, 105]. Based on the available results it seems that we should consider higher LDL-C levels for patients with the risk of hemorrhagic stroke $(70-100 \mathrm{mg} / \mathrm{dl})$ with the consideration of using non-statin drugs for these patients (PCSK9 inhibitors) [104-111].

Our study has some limitations. We observed a relatively high rate of heterogeneity with regard to the link between LDL concentration and stroke; thus, to obtain more reliable conclusions, more studies with higher resolution are needed. We had sufficient statistical power and a low level of type I and II error for the RCTs with regard to the total stroke and ischemic risk, but not for the hemorrhagic stroke, to obtain reliable results. Cohort studies were adjusted for the varied range of the co-variants, which might have led to the high level of the heterogeneity between studies. We performed TSA to evaluate and decrease the chance of type I and II error, which was a strength of the study.

In conclusion, our study sheds light on the debatable association between low LDL-C and different types of strokes. LDL-C reduction with available therapies is in general associated with the reduction of all strokes and ischemic strokes; such an association was not seen for hemorrhagic stroke, where no significant results were observed. This information can help determine the optimal LDL-C range for stroke prevention and help plan future LLA studies. Further studies are still needed to determine the effects of low to extremely low LDL-C levels on hemorrhagic stroke and the role of LLAs.

\section{Acknowledgments}

Drs Banach and Mazidi contributed equally to this analysis.

\section{Conflict of interest}

MB has received research grant(s)/support from Amgen, Sanofi Valeant, Viatris, and has served as a consultant for Abbott Medical, Amgen, Daichii Sankyo, Esperion, Herbapol, Kogen, KRKA, Polfarmex, Polpharma, Roche Diagnostics, Sanofi-Aventis, Servier, Teva, Zentiva; he is CMO at Nomi Biotech Corporation; DPM has given talks and attended conferences sponsored by MSD, AstraZeneca and Libytec; GYHL: Consultant for Bayer/Janssen, BMS/Pfizer, Medtronic, Boehringer Ingelheim, Novartis, Verseon and Daiichi-Sankyo. Speaker for Bayer, BMS/Pfizer, Medtronic, Boehringer Ingelheim, and Daiichi-Sankyo - no fees are directly received personally. The other authors declare no conflict of interest.

\section{References}

1. Anderson KM, Castelli WP, Levy D. Cholesterol and mortality: 30 years of follow-up from the Framingham Study. JAMA 1987; 257: 2176-80.

2. Stamler J, Wentworth D, Neaton JD. Is relationship between serum cholesterol and risk of premature death from coronary heart disease continuous and graded? Findings in 356222 primary screenees of the multiple risk factor intervention trial (mrfit). JAMA 1986; 256: 2823-8.

3. Koren-Morag N, Tanne D, Graff E, Goldbourt U. Low-and high-density lipoprotein cholesterol and ischemic cere- 
brovascular disease: the bezafibrate infarction prevention registry. Arch Intern Med 2002; 162: 993-9.

4. Bowman TS, Sesso HD, Ma J, et al. Cholesterol and the risk of ischemic stroke. Stroke 2003; 34: 2930-4.

5. Bots M, Elwood PC, Nikitin Y, et al. Total and HDL cholesterol and risk of stroke. EUROSTROKE: a collabora tive study among research centres in Europe. J Epidemiol Commun Health 2002; 56 (Suppl 1): i19-24.

6. Qizilbash N, Lewington S, Duffy S, et al. Cholesterol, diastolic blood pressure, and stroke: 13,000 strokes in 450,000 people in 45 prospective cohorts. Prospective studies collaboration. Lancet 1995; 346: 1647-53.

7. Shahar E, Chambless LE, Rosamond WD, et al. Plasma lipid profile and incident ischemic stroke: the Atherosclerosis Risk in Communities (ARIC) study. Stroke 2003; 34: 623-31.

8. Iso H, Jacobs Jr DR, Wentworth D, Neaton JD, Cohen JD, Group* MR. Serum cholesterol levels and six-year mortality from stroke in 350,977 men screened for the multiple risk factor intervention trial. N Engl J Med 1989; 320: 904-10.

9. Wannamethee SG, Shaper AG, Ebrahim S. HDL-cholesterol, total cholesterol, and the risk of stroke in middle-aged British men. Stroke 2000; 31: 1882-8.

10. Lewington S, Whitlock G, Clarke R, et al. Prospective Studies Collaboration Blood cholesterol and vascular mortality by age, sex, and blood pressure: a meta-analysis of individual data from 61 prospective studies with 55,000 vascular deaths. Lancet 2007; 370: 1829-39.

11. Amarenco P, Lavallée P, Touboul PJ. Stroke prevention, blood cholesterol, and statins. Lancet Neurol 2004; 3: 271-8.

12. Amarenco P, Labreuche J, Lavallée P, Touboul PJ. Statins in stroke prevention and carotid atherosclerosis: systematic review and up-to-date meta-analysis. Stroke 2004; 35: 2902-9.

13. Baigent C. Cholesterol Treatment Trialists'(CTT) Collaborators: Efficacy and safety of cholesterol-lowering treatment: prospective meta-analysis of data from 90,056 participants in 14 randomised trials of statins. Lancet 2005; 366: 1267-78.

14. Unit ES. Efficacy and safety of cholesterol-lowering treatment: prospective meta-analysis of data from 90056 participants in 14 randomised trials of statins. Lancet 2005; 366: 1267-78.

15. Imamura T, Doi Y, Arima H, et al. LDL cholesterol and the development of stroke subtypes and coronary heart disease in a general Japanese population: the Hisayama study. Stroke 2009; 40: 382-8.

16. Amarenco P, Labreuche J, Touboul PJ. High-density lipoprotein-cholesterol and risk of stroke and carotid atherosclerosis: a systematic review. Atherosclerosis 2008; 196: 489-96

17. Stone NJ, Robinson JG, Lichtenstein AH, et al. 2013 ACC/ AHA guideline on the treatment of blood cholesterol to reduce atherosclerotic cardiovascular risk in adults: a report of the American College of Cardiology/American Heart Association Task Force on Practice Guidelines. J Am Coll Cardiol 2014; 63(25 Part B): 2889-934.

18. Smith MB, Lee NJ, Haney E, Carson S. Drug class review: HMG-CoA reductase inhibitors (statins) and fixed-dose combination products containing a statin: final report update 5. Portland (OR): Oregon Health \& Science University; 2009 Nov.

19. Afilalo J, Duque G, Steele R, Jukema JW, de Craen AJ, Eisenberg MJ. Statins for secondary prevention in el- derly patients: a hierarchical bayesian meta-analysis. J Am Coll Cardiol 2008; 51: 37-45.

20. Roberts CG, Guallar E, Rodriguez A. Efficacy and safety of statin monotherapy in older adults: a meta-analysis. J Gerontol A Biol Sci Med Sci 2007; 62: 879-87.

21. Ward S, Jones ML, Pandor A, et al. A systematic review and economic evaluation of statins for the prevention of coronary events. NIHR Health Technology Assessment programme: Executive Summaries: NIHR Journals Library 2007.

22. Briel M, Studer M, Glass TR, Bucher HC. Effects of statins on stroke prevention in patients with and without coronary heart disease: a meta-analysis of randomized controlled trials. Am J Med 2004; 117 . 596-606.

23. Trialists CT. Efficacy and safety of LDL-lowering therapy among men and women: meta-analysis of individual data from 174000 participants in 27 randomised trials. Lancet 2015; 385: 1397-405.

24. Sabatine MS, Wiviott SD, Im K, Murphy SA, Giugliano RP. Efficacy and safety of further lowering of low-density lipoprotein cholesterol in patients starting with very low levels: a meta-analysis. JAMA Cardiol 2018; 3: 823-8.

25. Shepherd J, Cobbe SM, Ford I, et al. Prevention of coronary heart disease with pravastatin in men with hypercholesterolemia. N Engl J Med 1995; 333: 1301-8.

26. Downs JR, Clearfield $M$, Weis $S$, et al. Primary prevention of acute coronary events with lovastatin in men and women with average cholesterol levels: results of AFCAPS/TexCAPS. JAMA 1998; 279: 1615-22.

27. Group HPSC. MRC/BHF Heart Protection Study of cholesterol lowering with simvastatin in 20536 high-risk individuals: a randomised placebocontrolled trial. Lancet 2002; 360: 7-22.

28. Group HPSC. Effects of cholesterol-lowering with simvastatin on stroke and other major vascular events in 20536 people with cerebrovascular disease or other high-risk conditions. Lancet 2004; 363: 757-67.

29. Shepherd J, Blauw GJ, Murphy MB, et al. Pravastatin in elderly individuals at risk of vascular disease (PROSPER): a randomised controlled trial. Lancet 2002; 360: 1623-30.

30. Sever PS, Dahlöf B, Poulter NR, et al. Prevention of coronary and stroke events with atorvastatin in hypertensive patients who have average or lower-than-average cholesterol concentrations, in the Anglo-Scandinavian Cardiac Outcomes Trial - Lipid Lowering Arm (ASCOT-LLA): a multicentre randomised controlled trial. Lancet 2003; 361: 1149-58.

31. Athyros VG, Papageorgiou AA, Mercouris BR, et al. Treatment with atorvastatin to the National Cholesterol Educational Program goal versus' usual'care in secondary coronary heart disease prevention. Curr Med Res Opin 2002; 18: 220-8.

32. Schwartz GG, Steg PG, Szarek M, et al. Alirocumab and cardiovascular outcomes after acute coronary syndrome. N Engl J Med 2018; 379: 2097-107.

33. Sabatine MS, Giugliano RP, Keech AC, et al. Evolocumab and clinical outcomes in patients with cardiovascular disease. N Engl J Med 2017; 376: 1713-22.

34. Stroup DF, Berlin JA, Morton SC, et al. Meta-analysis of observational studies in epidemiology: a proposal for reporting. Meta-analysis Of Observational Studies in Epidemiology (MOOSE) group. JAMA 2000; 283: 2008-12.

35. Stang A. Critical evaluation of the Newcastle-Ottawa scale for the assessment of the quality of nonrandom- 
ized studies in meta-analyses. Eur J Epidemiol 2010; 25: 603-5.

36. Ferretti G, Bacchetti T, Sahebkar A. Effect of statin therapy on paraoxonase-1 status: a systematic review and meta-analysis of 25 clinical trials. Progress Lipid Res 2015; 60: 50-73.

37. Sahebkar A. Are curcuminoids effective C-reactive protein-lowering agents in clinical practice? Evidence from a meta-analysis. Phytother Res 2014; 28: 633-42.

38. Sahebkar A, Serban MC, Mikhailidis DP, et al. Head-tohead comparison of statins versus fibrates in reducing plasma fibrinogen concentrations: a systematic review and meta-analysis. Pharmacol Res 2016; 103: 236-52.

39. Duval S, Tweedie R. Trim and fill: a simple funnel-plotbased method of testing and adjusting for publication bias in meta-analysis. Biometrics 2000; 56: 455-63.

40. Borenstein M, Hedges L, Higgins J, Rothstein H. Comprehensive Metaanalysis (Vers. 2). Englewood Cliffs, NJ: Biostat. Inc; 2005.

41. Moher D, Liberati A, Tetzlaff J, Altman DG. Preferred reporting items for systematic reviews and meta-analyses: the PRISMA statement. Ann Intern Med 2009; 151: 264-9, W64.

42. Phan K, Tian DH, Cao C, Black D, Yan TD. Systematic review and meta-analysis: techniques and a guide for the academic surgeon. Ann Cardiothorac Surg 2015; 4: 112-22.

43. Higgins JPT GSe. Cochrane Handbook for Systematic Reviews of Interventions. Version 5.0.2. London: The Cochrane Collaboration 2009.

44. Amarenco P, Goldstein LB, Callahan A $3^{\text {rd }}$, et al. Baseline blood pressure, low- and high-density lipoproteins, and triglycerides and the risk of vascular events in the Stroke Prevention by Aggressive Reduction in Cholesterol Levels (SPARCL) trial. Atherosclerosis 2009; 204: 515-20.

45. Imamura T, Doi Y, Arima $\mathrm{H}$, et al. LDL cholesterol and the development of stroke subtypes and coronary heart disease in a general Japanese population: the Hisayama study. Stroke 2009; 40: 382-8.

46. Glasser SP, Mosher A, Howard G, Banach M. What is the association of lipid levels and incident stroke? Int J Cardiol 2016; 220: 890-4.

47. Psaty BM, Anderson M, Kronmal RA, et al. The association between lipid levels and the risks of incident myocardial infarction, stroke, and total mortality: the Cardiovascular Health Study. J Am Geriatr Soc 2004; 52: 1639-47.

48. Stoekenbroek RM, Boekholdt SM, Luben R, et al. Heterogeneous impact of classic atherosclerotic risk factors on different arterial territories: the EPIC-Norfolk prospective population study. Eur Heart J 2016; 37: 880-9.

49. Holme I, Aastveit AH, Hammar N, Jungner I, Walldius $\mathrm{G}$. Relationships between lipoprotein components and risk of ischaemic and haemorrhagic stroke in the Apolipoprotein MOrtality RISk study (AMORIS). J Intern Med 2009; 265: 275-87.

50. Wieberdink RG, Poels MM, Vernooij MW, et al. Serum lipid levels and the risk of intracerebral hemorrhage: the Rotterdam Study. Arterioscler Thromb Vasc Biol 2011; 31: 2982-9.

51. Ma C, Gurol ME, Huang Z, et al. Low-density lipoprotein cholesterol and risk of intracerebral hemorrhage: a prospective study. Neurology 2019; 93: e445-57.

52. Nakaya N, Kita T, Mabuchi H, et al. Large-scale cohort study on the relationship between serum lipid concentrations and risk of cerebrovascular disease under low-dose simvastatin in Japanese patients with hypercholesterolemia: sub-analysis of the Japan Lipid Intervention Trial (J-LIT). Circulation 2005; 69: 1016-21.

53. Furberg C, Wright J, Davis B, Cutler J, Alderman $M$, Black $\mathrm{H}$. The ALLHAT Officers and Coordinators for the ALLHAT Collaborative Research Group, et al. Major outcomes in high-risk hypertensive patients randomized to angiotensinconverting enzyme inhibitor or calcium channel blocker vs diuretic. The antihypertensive and lipid-lowering treatment to prevent heart attack trial (ALLHAT). JAMA 2002; 288: 2981-97.

54. Koren MJ, Hunninghake DB, investigators A. Clinical outcomes in managed-care patients with coronary heart disease treated aggressively in lipid-lowering disease management clinics: the alliance study. J Am Coll Cardiol 2004; 44: 1772-9.

55. Tavazzi L, Maggioni AP, Marchioli R, et al. Effect of rosuvastatin in patients with chronic heart failure (the GISSI-HF trial): a randomised, double-blind, placebocontrolled trial. Lancet 2008; 372: 1231-9.

56. Holdaas H, Fellström B, Jardine AG, et al. Effect of fluvastatin on cardiac outcomes in renal transplant recipients: a multicentre, randomised, placebo-controlled trial. Lancet 2003; 361: 2024-31.

57. Pedersen TR, Faergeman O, Kastelein JJ, et al. Highdose atorvastatin vs usual-dose simvastatin for secondary prevention after myocardial infarction: the IDEAL study: a randomized controlled trial. JAMA 2005; 294: 2437-45.

58. LaRosa JC, Grundy SM, Waters DD, et al. Intensive lipid lowering with atorvastatin in patients with stable coronary disease. N Engl J Med 2005; 352: 1425-35.

59. Knopp RH, d'Emden M, Smilde JG, Pocock SJ. Efficacy and safety of atorvastatin in the prevention of cardiovascular end points in subjects with type 2 diabetes: the Atorvastatin Study for Prevention of Coronary Heart Disease Endpoints in non-insulin-dependent diabetes mellitus (ASPEN). Diabetes Care 2006; 29: 1478-85.

60. Investigators SPbARiCL. High-dose atorvastatin after stroke or transient ischemic attack. N Engl J Med 2006; 355: 549-59.

61. Ridker PM, Danielson E, Fonseca FA, et al. Rosuvastatin to prevent vascular events in men and women with elevated C-reactive protein. N Engl J Med 2008; 359: 2195-207.

62. Fellström BC, Jardine AG, Schmieder RE, et al. Rosuvastatin and cardiovascular events in patients undergoing hemodialysis. N Engl J Med 2009; 360: 1395-407.

63. Baigent C, Landray MJ, Reith C, et al. The effects of lowering LDL cholesterol with simvastatin plus ezetimibe in patients with chronic kidney disease (Study of Heart and Renal Protection): a randomised placebo-controlled trial. Lancet 2011; 377: 2181-92.

64. Cannon CP, Blazing MA, Giugliano RP, et al. Ezetimibe added to statin therapy after acute coronary syndromes. N Engl J Med 2015; 372: 2387-97.

65. Sacco RL, Benson RT, Kargman DE, et al. High-density lipoprotein cholesterol and ischemic stroke in the elderly: the Northern Manhattan Stroke Study. JAMA 2001; 285: 2729-35.

66. Lindenstrom E, Boysen G, Nyboe J. Influence of total cholesterol, high density lipoprotein cholesterol, and triglycerides on risk of cerebrovascular disease: the Copenhagen City Heart Study. BMJ 1994; 309: 11-5.

67. Bejot Y, Benatru I, Rouaud O, et al. Epidemiology of stroke in Europe: geographic and environmental differences. J Neurol Sci 2007; 262: 85-8. 
68. Shaper A, Phillips A, Pocock S, Walker M, Macfarlane P. Risk factors for stroke in middle aged British men. BMJ 1991; 302: 1111-5.

69. Soyama Y, Miura K, Morikawa Y, et al. High-density lipoprotein cholesterol and risk of stroke in Japanese men and women: the Oyabe Study. Stroke 2003; 34: 863-8.

70. Bruckdorfer K, Demel R, Gier JD, Van Deenen L. The effect of partial replacements of membrane cholesterol by other steroids on the osmotic fragility and glycerol permeability of erythrocytes. Biochim Biophys Acta 1969; 183: 334-45.

71. Konishi $\mathrm{M}$, Iso $\mathrm{H}$, Komachi Y, et al. Associations of serum total cholesterol, different types of stroke, and stenosis distribution of cerebral arteries. The Akita Pathology Study. Stroke 1993; 24: 954-64.

72. Ariesen M, Claus S, Rinkel G, Algra A. Risk factors for intracerebral hemorrhage in the general population: a systematic review. Stroke 2003; 34: 2060-5.

73. Noda $\mathrm{H}$, Iso $\mathrm{H}$, Irie $\mathrm{F}$, et al. Low-density lipoprotein cholesterol concentrations and death due to intraparenchymal hemorrhage: the Ibaraki Prefectural Health Study. Circulation 2009; 119: 2136-45

74. Yamori Y, Nara Y, Horie R, Ooshima A. Abnormal membrane characteristics of erythrocytes in rat models and men with predisposition to stroke. Clin Exp Hypertens 1980; 2: 1009-21.

75. Rosenson RS, Lowe GD. Effects of lipids and lipoproteins on thrombosis and rheology. Atherosclerosis 1998; 140: 271-80.

76. Hoffman CJ, Lawson WE, Miller RH, Hultin MB. Correlation of vitamin $\mathrm{K}$-dependent clotting factors with cholesterol and triglycerides in healthy young adults. Arterioscler Thromb 1994; 14: 1737-40.

77. Kim DE, Bae HJ, Lee SH, Kim H, Yoon BW, Roh JK. Gradient echo magnetic resonance imaging in the predic tion of hemorrhagic vs ischemic stroke: a need for the consideration of the extent of leukoariosis. Arch Neurol 2002; 59: 425-9.

78. Trialists CT. Efficacy and safety of more intensive lowering of LDL cholesterol: a meta-analysis of data from 170000 participants in 26 randomised trials. Lancet 2010; 376: 1670-81.

79. Amarenco P, Labreuche J. Lipid management in the prevention of stroke: review and updated meta-analysis of statins for stroke prevention. Lancet Neurol 2009; 8: 453-63.

80. Shin J, Chung JW, Jang HS, et al. Achieved low-density lipoprotein cholesterol level and stroke risk: a meta-analysis of 23 randomised trials. Eur J Prev Cardiol 2019:2047487319830503.

81. Amarenco P, Goldstein LB, Callahan III A, et al. Baseline blood pressure, low-and high-density lipoproteins, and triglycerides and the risk of vascular events in the Stroke Prevention by Aggressive Reduction in Cholesterol Levels (SPARCL) trial. Atherosclerosis 2009; 204 . 515-20.

82. Patel A, Woodward M, Campbell DJ, et al. Plasma lipids predict myocardial infarction, but not stroke, in patients with established cerebrovascular disease. Eur Heart J 2005; 26: 1910-5.

83. Glasser SP, Mosher A, Howard G, Banach M. What is the association of lipid levels and incident stroke? Int J Cardiol 2016; 220: 890-4

84. Silverman MG, Ference BA, Im K, et al. Association between lowering LDL-C and cardiovascular risk reduc tion among different therapeutic interventions: a sys- tematic review and meta-analysis. JAMA 2016; 316: 1289-97.

85. Gordon T, Kannel WB, Castelli WP, Dawber TR. Lipoproteins, cardiovascular disease, and death: the Framing ham Study. Arch Intern Med 1981; 141: 1128-31.

86. Giugliano RP, Wiviott SD, Blazing MA, et al. Long-term safety and efficacy of achieving very low levels of low-density lipoprotein cholesterol: a prespecified analysis of the IMPROVE-IT trial. JAMA Cardiol 2017; 2: 547-55

87. Giugliano RP, Pedersen TR, Park JG, et al. Clinical efficacy and safety of achieving very low LDL-cholesterol concentrations with the PCSK9 inhibitor evolocumab: a prespecified secondary analysis of the FOURIER trial. Lancet 2017; 390: 1962-71.

88. Ridker PM, Morrow DA, Rose LM, Rifai N, Cannon CP, Braunwald E. Relative efficacy of atorvastatin $80 \mathrm{mg}$ and pravastatin $40 \mathrm{mg}$ in achieving the dual goals of low-density lipoprotein cholesterol< $70 \mathrm{mg} / \mathrm{dl}$ and C-reactive protein < $2 \mathrm{mg} / \mathrm{l}$ : an analysis of the PROVE-IT TIMI-22 trial. J Am Coll Cardiol 2005; 45: 1644-8.

89. Schoenhagen P, Tuzcu EM, Apperson-Hansen C, et al. Determinants of arterial wall remodeling during lipid-lowering therapy: serial intravascular ultrasound observations from the Reversal of Atherosclerosis with Aggressive Lipid Lowering Therapy (REVERSAL) trial. Circulation 2006; 113: 2826-34

90. Nissen SE, Nicholls SJ, Sipahi I, et al. Effect of very high-intensity statin therapy on regression of coronary atherosclerosis: the ASTEROID trial. JAMA 2006; 295: 1556-65.

91. Ridker PM, Danielson E, Fonseca FA, et al. Reduction in C-reactive protein and LDL cholesterol and cardiovascular event rates after initiation of rosuvastatin: a prospective study of the JUPITER trial. Lancet 2009; 373: 1175-82.

92. Nakaya N, Kita T, Mabuchi H, et al. Large-scale cohort study on the relationship between serum lipid concentrations and risk of cerebrovascular disease under low-dose simvastatin in Japanese patients with hypercholesterolemia. Circ J 2005; 69: 1016-21.

93. Wieberdink RG, Poels MM, Vernooij MW, et al. Serum lipid levels and the risk of intracerebral hemorrhage: the Rotterdam Study. Arterioscler Thromb Vasc Biol 2011; 31: 2982-9.

94. Psaty BM, Anderson M, Kronmal RA, et al. The association between lipid levels and the risks of incident myocardial infarction, stroke, and total mortality: the Cardiovascular Health Study. J Am Geriatr Soc 2004; 52: 1639-47

95. Stoekenbroek RM, Boekholdt SM, Luben R, et al. Heterogeneous impact of classic atherosclerotic risk factors on different arterial territories: the EPIC-Norfolk prospective population study. Eur Heart J 2015; 37: 880-9.

96. Ritz K, Denswil NP, Stam OC, van Lieshout JJ, Daemen MJ. Cause and mechanisms of intracranial atherosclerosis. Circulation 2014; 130: 1407-14.

97. Sturgeon JD, Folsom AR, Longstreth Jr W, Shahar E, Ro samond WD, Cushman M. Risk factors for intracerebral hemorrhage in a pooled prospective study. Stroke 2007; 38: 2718-25.

98. Trialists CT. Efficacy and safety of cholesterol-lowering treatment: prospective meta-analysis of data from 90056 participants in 14 randomised trials of statins. Lancet 2005; 366: 1267-78.

99. Amarenco P, Goldstein LB, Szarek M, et al. Effects of intense low-density lipoprotein cholesterol reduction in patients with stroke or transient ischemic attack: the 
Stroke Prevention by Aggressive Reduction in Cholesterol Levels (SPARCL) trial. Stroke 2007; 38: 3198-204.

100. Bohula EA, Wiviott SD, Giugliano RP, et al. Prevention of stroke with the addition of ezetimibe to statin therapy in patients with acute coronary syndrome in IMPROVE-IT (Improved Reduction of Outcomes: Vytorin Efficacy International Trial). Circulation 2017; 136: 2440-50.

101. Milionis H, Barkas F, Ntaios G, et al. Proprotein convertase subtilisin kexin 9 (PCSK9) inhibitors to treat hypercholesterolemia: effect on stroke risk. Eur J Intern Med 2016; 34: 54-7.

102. Tran-Dinh A, Levoye A, Lambert G, et al. Low levels of low-density lipoprotein- $C$ associated with proprotein convertase subtilisin kexin 9 inhibition do not increase the risk of hemorrhagic transformation. Stroke 2014; 45: 3086-8.

103. Colhoun HM, Betteridge DJ, Durrington PN, et al. Primary prevention of cardiovascular disease with atorvastatin in type 2 diabetes in the Collaborative Atorvastatin Diabetes Study (CARDS): multicentre randomised placebo-controlled trial. Lancet 2004; 364: 685-96.

104. Masson W, Lobo M, Siniawski D, Masson G, Lavalle-Cobo A, Molinero G. LDL-C levels below $55 \mathrm{mg} / \mathrm{dl}$ and risk of hemorrhagic stroke: a meta-analysis. J Stroke Cerebrovasc Dis 2021; 30: 105655.

105. Sanz-Cuesta BE, Saver JL. Lipid-lowering therapy and hemorrhagic stroke risk: comparative meta-analysis of statins and PCSK9 inhibitors. Stroke 2021; 52: 3142-50.

106. Banach M, Burchardt P, Chlebus K, et al. PoLA/CFPiP/ PCS/PSLD/PSD/PSH guidelines on diagnosis and therapy of lipid disorders in Poland 2021. Arch Med Sci 2021; 17: 1447-547.

107. Labuz-Roszak B, Banach M, Skrzypek M, et al.; The Lipidogram Investigators. Secondary stroke prevention in polish adults: results from the LIPIDOGRAM2015 Study. J Clin Med 2021; 10: 4472.

108. Hutanu A, Iancu M, Dobreanu M, et al. Extended lipid profile in Romanian ischemic stroke patients in relation to stroke severity and outcome: a path analysis model. Arch Med Sci 2021; 17: 864-73.

109. Banach M, López-Sendon JL, Averna M, et al. Treatment adherence and effect of concurrent statin intensity on the efficacy and safety of alirocumab in a real-life setting: results from ODYSSEY APPRISE. Arch Med Sci 2021; 18: 285-92.

110. Solnica B, Sygitowicz G, Sitkiewicz D, et al. 2020 Guidelines of the Polish Society of Laboratory Diagnostics (PSLD) and the Polish Lipid Association (PoLA) on laboratory diagnostics of lipid metabolism disorders. Arch Med Sci 2020; 16: 237-52.

111. Banach M, Mikhailidis DP, Kjeldsen SE, Rysz J. Time for new indications for statins? Med Sci Monit 2009; 15: MS1-5. 